\title{
Caracterização isotópica e qualidade das águas subterrâneas no município de Serra do Ramalho, Bahia (Brasil)
}

\author{
Manuel Vitor Portugal Gonçalves ${ }^{1 *}$ \\ Rodrigo Alves Santos ${ }^{1}$ \\ Antônio Bomfim da Silva Ramos Junior ${ }^{1}$ \\ Flavio Souza Batista ${ }^{1}$ \\ Ana Carina Matos Silva ${ }^{1}$ \\ Manoel Jerônimo Moreira Cruz ${ }^{1}$ \\ Alexandre Barreto Costa ${ }^{2}$ \\ Grupo Geoquímica das Interfaces \\ Instituto de Geociências \\ Universidade Federal da Bahia \\ Rua Barão de Geremoabo S/N, Campus Ondina \\ Salvador BA Brasil \\ CEP 40170-115 \\ Programa de Pós-Graduação em Geofísica \\ Instituto de Física \\ Universidade Federal da Bahia \\ Rua Caetano Moura, 123 Federação \\ Salvador BA Brasil. \\ CEP 40210-340 \\ ${ }^{*}$ Corresponding author: \\ zoovitor81@yahoo.com.br
}

\section{RESUMO}

Esta pesquisa teve como objetivo investigar a composição dos isótopos estáveis $\left(\delta^{2} \mathrm{H}\right.$ e $\left.\delta^{18} \mathrm{O}\right)$ e a qualidade das águas subterrâneas do município Serra do Ramalho, Bahia, Brasil. Foram coletadas amostras de água de 26 poços perfurados nas rochas pelito-carbonáticas do Grupo Bambuí e mensuradas in situ as variáveis físico-químicas ( $\mathrm{pH}, \mathrm{CE}, \mathrm{STD}, \mathrm{ORP})$, por meio de sonda multiparâmetros, e efetuadas análises laboratoriais dos cátions (ICP-OES), ânions $\left(\mathrm{HCO}_{3}^{-}, \mathrm{Cl}^{-}, \mathrm{SO}_{4}{ }^{2-}, \mathrm{N}-\mathrm{NO}_{2}^{-}, \mathrm{N}_{-} \mathrm{NO}_{3}^{-}, \mathrm{F}^{-}\right)$e isótopos estáveis (IRMS-MS). Os valores da razão isotópica destacaram o papel da recarga pelas chuvas locais, infiltração rápida e pouca evaporação. A análise de agrupamento indicou haver quatro grupos hidroquímicos, que diferiram quanto aos valores dos STD, $\mathrm{Na}^{+}, \mathrm{Cl}^{-}$ , índices de saturação e das razões geoquímicas, variando a composição geoquímica das águas bicarbonatadas cálcicas ou mistas cálcicas para as bicarbonatadas ou cloretadas sódicas, em função da interação água-rocha, reações de troca de bases e intemperismo químico das fases minerais constituintes ou acessórias nas rochas pelito-carbonáticas, do clima e circulação da água no aquífero. Caberia o monitoramento dos teores do nitrato, fluoreto e metais-traço e a efetivação da vigilância ambiental em saúde, com a formação de profissionais que considerem a saúde em suas múltiplas relações com o meio ambiente.

Palavras-Chave: Hidrologia Isotópica; Análise Multivariada; Recursos Hídricos; Aquífero Bambuí.

\section{ABSTRACT}

This research aimed to investigate the composition of stable isotopes $\left(\delta^{2} \mathrm{H}\right.$ and $\delta^{18} \mathrm{O}$ ) and groundwater quality of Serra do Ramalho municipality, Bahia, Brazil. Water samples were collected from 26 tubular wells drilled in the pellet-carbonate rocks of the Bambuí Group. The physico-chemical variables $(\mathrm{pH}, \mathrm{EC}, \mathrm{ORP}$, STD) were measured in situ, using multiparameter probes, cations (ICP-OES), anions $\left(\mathrm{HCO}_{3}^{-}, \mathrm{Cl}^{-}, \mathrm{SO}_{4}{ }^{2-}, \mathrm{N}-\mathrm{NO}_{2}^{-}, \mathrm{N}-\mathrm{NO}_{3}^{-}, \mathrm{F}^{-}\right)$and stable isotopes (IRMS-MS). The isotopic ratio values suggested the role of recharge by local rainfall, rapid infiltration and low evaporation. Cluster analysis indicated that there were four hydrochemical groups that differed for the values of TDS, $\mathrm{Na}^{+}, \mathrm{Cl}^{-}$, saturation indices and geochemical ratios, varying the geochemical composition of the calcium bicarbonate or mixed chloricated waters to the bicarbonate or sodium chloride, resulting from the water-rock interaction, base exchange reactions and chemical weathering of the constituent or accessories mineral phases in the pelitocarbonate rocks, climate and circulation water in the aquifer. It is recommended to monitor the levels of nitrate, fluoride and trace metals and to carry out environmental surveillance in health, with the training of professionals who consider health in its multiple relations with the environment.

Keywords: Isotopic Hydrology; Multivariate Statistics; Water Resources; Bambuí Aquifer. 


\section{INTRODUÇÃO}

O gerenciamento da qualidade da água deve ser universal e alvo da atenção dos planejadores de saúde pública e dos recursos hídricos, sendo essencial para o desenvolvimento humano e social. As águas subterrâneas podem conter íons dissolvidos em níveis tóxicos, a exemplo das espécies químicas nitrogenadas, cujo consumo promove agravos à saúde humana (BIGUELINI; GUMY, 2012). De acordo com Reynolds-Vargas et al. (2006), o nitrato se situa entre os poluentes inorgânicos mais estudado e frequentes nas águas subterrâneas. Destacam-se, dentre as fontes do nitrato que poluem os aquíferos, no mundo, a utilização indevida de fertilizantes com nitrogênio na agricultura, o manejo do solo, a pecuária, o lançamento de esgotos in natura e a deposição atmosférica (BAIRD; CANN, 2011).

Os altos teores do nitrato nas águas subterrâneas configuram um desafio higiênicosanitário, porque este poluente pode ser facilmente lixiviado da solução do solo, ou no perfil do aquífero, sendo persistente em condições aeróbicas (VARNIER et al., 2010). Nos aquíferos cárstico, verifica-se uma alta vulnerabilidade intrínseca a poluentes, a exemplo do nitrato, por conta das feições características de dissolução que são encontradas nestes meios (RIBEIRO, et al., 2011; SANTOS, 2017; GASSER et al., 2018).

Nos aquíferos cársticos, a investigação hidrogeológica ou hidrogeoquímica exige a aplicação conjunta de métodos diversos, em função das incertezas associadas à carstificação (SILVA JÚNIOR; CUSTÓDIO, 2010). A razão isotópica da molécula da água representa um método de estudo adicional da zona insaturada em meios cársticos, uma vez que esta não muda na interação água-rocha sob baixas temperaturas, propiciando a utilização dos isótopos estáveis como traçadores físicos na hidrologia (KOHFAHL et al. 2008; SÁNCHEZ et al., 2015). Os isótopos estáveis da molécula da água informam quanto a recarga, circulação e tempo de residência relativo da água no aquífero (CLARK; FRITZ, 1997).

Craig (1957) e Dansgaard (1964) pesquisaram as correlações entre as razões isotópicas do oxigênio e hidrogênio da água, e avaliaram os principais fatores ou "efeitos" que influenciam a razão isotópica da água meteórica. Apontaram os efeitos da temperatura, sazonalidade, quantidade das chuvas, latitude e a distância da costa. Estes "efeitos" se relacionam a retirada da umidade da atmosfera decorrente do resfriamento da massa de ar, em que a temperatura é um fator preponderante.

Craig (1957) e Dansgaard (1964) obtiveram a curva para as águas meteóricas, cuja reta é $\delta \mathrm{D}=$ $8 \delta^{18} \mathrm{O}+\mathrm{d}$, sendo o "excesso de deutério" (d) de $10 \%$ para a linha meteórica global (LMG). O excesso de deutério reflete $\mathrm{o}$ fracionamento cinético, processos de não-equilíbrio, as condições meteorológicas e a distância de fontes evaporativas de origem das precipitações (MERLIVAT; JOUZEL, 1979; ARMENGAUD et. al., 1998). A razão isotópica empobrece quanto ao isótopo pesado em função da distância da fonte de vapor e o efeito quantidade decorre da variabilidade sazonal da intensidade das precipitações atribuída à influência da temperatura sobre a trajetória da massa de ar, ou do "excesso de deutério".

Ghesquière et al. (2015) entendem que a aplicação integrada de técnicas químicas, isotópicas e estatísticas multivariada disponibilizam informações sobre a hidrogeoquímica, interação água-rocha e fluxo subterrâneo e qualidade das águas. A composição hidrogeoquímica de aquíferos cársticos varia em função do tempo de residência, da distância percorrida, da mineralogia e das rochas encaixantes (MORAL et al., 2008). Nesta perspectiva, Liu et al. (2015) esclarecem que o conhecimento sobre a origem e o comportamento dos íons principais $\left(\mathrm{Ca}^{2+}, \mathrm{Mg}^{2+}, \mathrm{Na}^{+}, \mathrm{K}^{+}, \mathrm{CO}_{3}{ }^{2-}-\right.$ $\left.\mathrm{HCO}_{3}{ }^{-}, \mathrm{Cl}^{-}, \mathrm{SO}_{4}{ }^{2-}\right)$ na água subterrânea são essenciais para a compreensão da geoquímica e aspectos da qualidade das águas.

A composição geoquímica das águas do Aquífero Bambuí no Oeste Bahia varia de acordo com o clima e composição mineralógica das rochas do Grupo Bambuí (GONÇALVES et al., 2018). No município de Serra do Ramalho, Bahia, as águas subterrâneas que são captadas pela rede de poços tubulares dispostos nas rochas do Grupo Bambuí auxiliam no abastecimento público, em especial nas áreas periféricas e rurais, como nas localidades de Mata Verde, Taquari e Mandiaçu, que configuram assentamentos do Instituto Nacional de Colonização e Reforma Agrária - Incra. Entretanto, as informações hidroquímicas ou isotópicas aplicáveis ao gerenciamento da qualidade da água são escassas ou incipientes. Esta pesquisa teve como objetivo investigar a composição isotópica $\left(\delta^{2} \mathrm{H}\right.$ e $\left.\delta^{18} \mathrm{O}\right)$ e à qualidade das águas subterrâneas do município Serra do Ramalho, no Oeste da Bahia, Brasil. 


\section{CARACTERIZAÇÃO DA ÁREA DE ESTUDO}

O município de Serra do Ramalho tem uma área de $2.342 \mathrm{~km}^{2}$ (Figura 1) e possuía em 2010, de acordo com censo demográfico do IBGE (2010): população de 31.638 habitantes, Produto Interno Bruto (PIB) de 124.793, 000 mil reais, $2,5 \%$ dos domicílios abrangendo esgotamento sanitário adequado e Índice de Desenvolvimento
Humano Municipal (IDH-M) de 0,595. Este município se situa na posição $176^{\circ}$ em relação aos 417 municípios da Bahia quanto ao IDH-M, ocupando as posições $91^{\circ}$ para o trabalho e renda, $136^{\circ}$ no tocante ao PIB, $199^{\circ}$ quanto a educação e $285^{\circ}$ em relação ao esgotamento sanitário adequado.

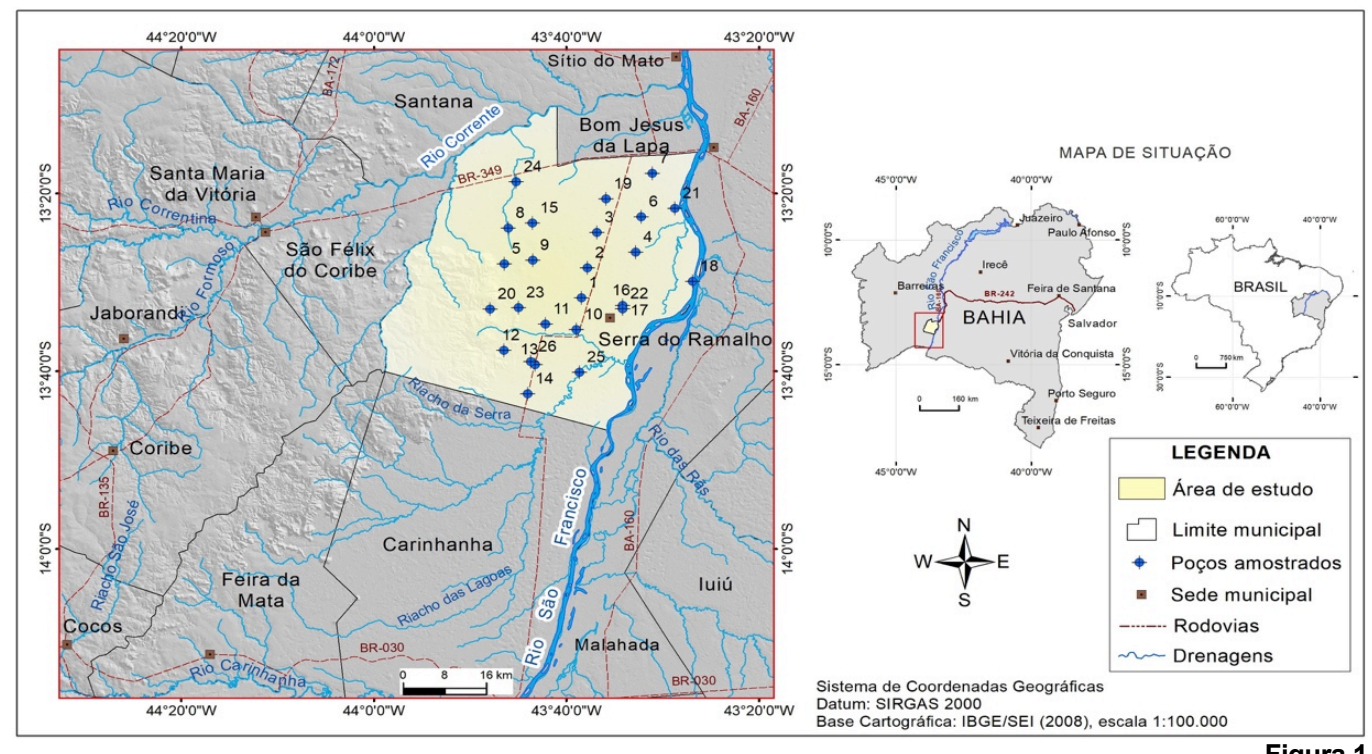

Mapa de localização e indicação dos pontos amostrais do município de Serra do Ramalho, Bahia, Brasil.

Este município apresenta como principais atividades econômicas na composição do PIB, em ordem decrescente de importância, a seguinte distribuição: serviços $(73 \%)$, agropecuário $(19 \%)$, setor industrial (4\%) e outros (4\%). Ressalta-se a relevância da produção de polpa de frutas e pecuária leiteira na constituição do setor agropecuário, podendo ser adicionado a agricultura familiar e de subsistência nos Assentamentos da Reserva Oeste e área rural de Serra do Ramalho, onde reside, segundo o IBGE (2010), um volume total de $80 \%$ da população. $\mathrm{Na}$ área urbana, as oportunidades econômicas e os serviços da administração pública concentram-se no entorno da sede municipal (Agrovila 9), e nas Agrovilas vizinhas.

A região do Oeste da Bahia, onde se situa Serra do Ramalho, apresenta uma classificação climática entre subúmido a semiárido, com temperaturas máxima e média anuais de $31,7^{\circ} \mathrm{C}$ e $25,6{ }^{\circ} \mathrm{C}$. As precipitações médias variam entre 800 e $1.010 \mathrm{~mm} / \mathrm{ano}$, de modo que as chuvas se concentram de novembro a abril e o período de estiagem situa-se entre os meses de maio a outubro (INMET, 2016).

$\mathrm{Na}$ geologia local afloram as litofácies neoproterozóicas carbonáticas da Formação Sete Lagoas e os pelitos (siltitos, folhelhos) da
Formação Serra de Santa Helena do Grupo Bambuí, depositadas sobre o embasamento gnáissico-migmatítico, Arqueano-Paleoproterozóico (MISI et al., 2011). Os poços tubulares de Serra do Ramalho foram perfurados nas rochas do Grupo Bambuí, as quais hospedam o Aquífero Bambuí (Figura 2). Os arenitos que hospedam o Aquífero Urucuia, depositados sobre o Grupo Bambuí, contribuem, junto às águas das chuvas, para a recarga do Aquífero Bambuí. Segundo Misi et al. (2007), a fase mineral fluorita ocorre disseminada e hospedada, principalmente, nas litofácies calcários e dolomitos da Formação Sete Lagoas na Província Cárstica do Oeste da Bahia.

No contexto hidrogeológico, pode ser observada uma direção preferencial do fluxo das águas subterrâneas, as quais se deslocam de oeste para leste, na direção do Rio São Francisco, considerado o nível de base regional, na Província Cárstica do Oeste do Estado da Bahia. Observa-se, igualmente, o alto topográfico da Serra do Ramalho, que representa um importante divisor de águas regional, e uma direção secundária de fluxo, o qual se desloca de oeste para sudeste, na direção do Rio Carinhanha. 


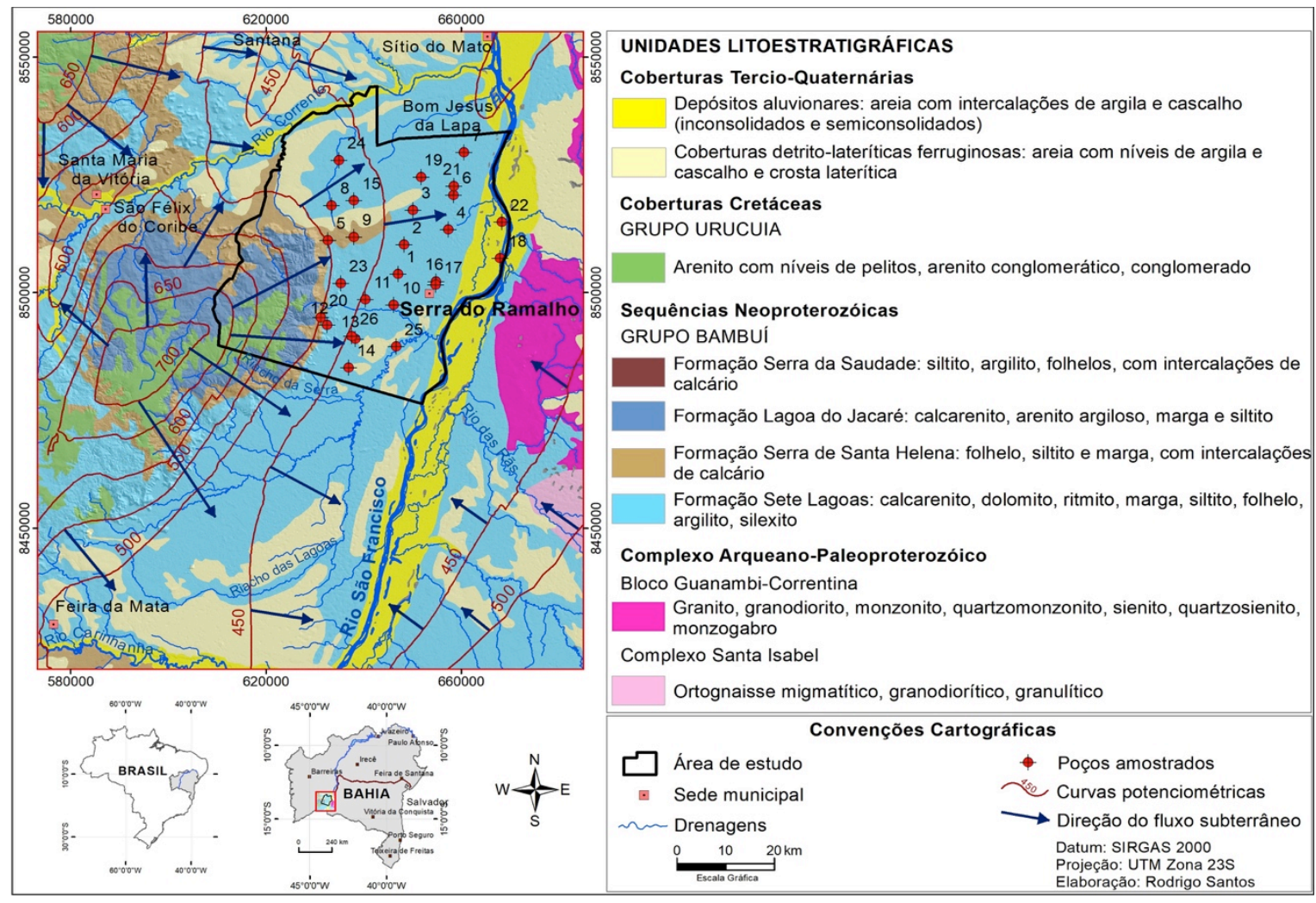

Figura 2

Mapa geológico simplificado e distribuição das superfícies potenciométricas no Aquífero Bambuí, no Oeste da Bahia, Brasil. Verifica-se, também, a indicação espacial dos pontos amostrais na área de estudo.

\section{MATERIAIS E MÉTODOS}

\subsection{COMPOSIÇÃO E MODELAGEM HIDROQUÍMICA}

Procedeu-se com a coleta de água de 26 poços tubulares dispostos nas rochas do Grupo Bambuí (Figuras 1 e 2), em janeiro de 2010 e novembro de 2011 (período chuvoso) e 2012 (estiagem). Foram determinadas, in situ, as variáveis ORP (potencial de oxirredução), $\mathrm{pH}$, condutividade elétrica $(\mathrm{CE})$ e sólidos totais dissolvidos (STD), por uma sonda multiparâmetros (Horiba U-50), e tomadas alíquotas para as análises no Laboratório do Plasma da Universidade Federal da Bahia (UFBA).

As alíquotas foram armazenadas em recipientes de polietileno $(0,5 \mathrm{~L}$ e $1 \mathrm{~L})$ e âmbar $(100 \mathrm{~mL})$, de acordo com as orientações da APHA (1995). As alíquotas de 0,5 L passaram por um filtro de acetato de celulose $0,45 \mu \mathrm{m}$ e pela adição de ácido nítrico até atingirem $\mathrm{pH}<$ 2 nas análises de cátions $\left(\mathrm{Na}^{+}, \mathrm{K}^{+}, \mathrm{Ca}^{2+}, \mathrm{Mg}^{2+}\right.$, $\left.\mathrm{Fe}^{2+}, \mathrm{Al}^{3+}, \mathrm{Ba}^{2+}, \mathrm{Cu}^{2+}, \mathrm{Cd}^{2+}, \mathrm{Mn}^{2+}, \mathrm{Zn}^{3+}, \mathrm{Pb}^{2+}\right)$. As alíquotas de $1 \mathrm{~L}$ foram destinadas às análises aniônica $\left(\mathrm{CO}_{3}{ }^{2-}, \mathrm{HCO}_{3}^{-}, \mathrm{NO}_{2}^{-}, \mathrm{NO}_{3}{ }^{-}\right.$, $\left.\mathrm{Cl}^{-}, \mathrm{SO}_{4}{ }^{2-}\right)(1 \mathrm{~L})$ e aquelas reservadas para as análises dos isótopos estáveis da água $\left(\delta^{18} \mathrm{O}\right.$, $\left.\delta^{2} \mathrm{H}\right)(100 \mathrm{~mL})$ permaneceram in natura, a temperatura de $\pm 4^{\circ} \mathrm{C}$.

Os teores dos cátions foram obtidos em duplicata, com $20 \%$ de triplicatas, por espectrometria de emissão óptica com plasma indutivamente acoplado (ICP-OES). As leituras dos ânions deram-se pelos métodos titrimétrico $\left(\mathrm{HCO}_{3}^{-}, \mathrm{Cl}^{-}\right)$, espectrofotométrico UV-VIS (Varian) $\left(\mathrm{SO}_{4}^{-2}, \mathrm{NO}_{2}^{-}, \mathrm{NO}_{3}^{-}\right)(1 \mathrm{~L}) \mathrm{e}$ colorimetria $\left(\mathrm{F}^{-}\right)$(SPADNS), com auxílio de um fluorímetro ( $L S$ 4000). A utilização dos softwares Diagrammes (6.52) e PHREEQC (PARKHURST; APPELO, 2013) permitiu o cálculo do índice de saturação (IS) das amostras, sendo agrupadas como subsaturada (IS < -0,5), em equilíbrio químico com a solução (IS: $-0,5$ e 0,5 ) e supersaturada (IS > 0,5). Merkel e Planer-Friedrich (2012) sugeriram a admissão de valores do IS superiores ao intervalo $0 \pm 0,5$, por conta das incertezas relacionadas ao cálculo deste ou associada a constante de equilíbrio do mineral dissolvido e das análises químicas. 


\subsection{ISÓTOPOS AMBIENTAIS}

A razão isotópica foi obtida por espectrometria de massa da razão isotópica (IRMS-MS), segundo a International Atomic Energy Agency (IAEA), no Laboratório de Física Nuclear Aplicada (UFBA), pelos métodos: i) razão deutério-hidrogênio $(\mathrm{D} / \mathrm{H})$ (Brand et al., 2000); e ii) razão ${ }^{18} \mathrm{O} /{ }^{16} \mathrm{O}$ (Epstein; Mayeda, 1953). Obteve-se a razão isotópica das amostras a partir do desvio em

\subsection{ABORDAGEM ESTATÍSTICA}

A análise estatística abrangeu o teste de normalidade (Shapiro-Wilk) e testes de comparações múltiplas paramétrica (ANOVA) ou não-paramétrica (Kruskal-Wallis), com nível de confiança de $95 \%$, e a análise de agrupamento (cluster analysis), com auxílio dos softwares STATISTICA 7.0, BioEstat 5.3 e Instat 3. A análise de agrupamento utiliza a similaridade entre os indivíduos para

\section{RESULTADOS E DISCUSSÃO}

\subsection{HIDROGEOQUÍMICA E ANÁLISE DE AGRUPAMENTO}

As amostras foram classificadas em fácies hidroquímicas bicarbonatadas cálcicas $\left(\mathrm{HCO}_{3}{ }^{-}\right.$ $\left.-\mathrm{Ca}^{2+}\right)(64 \%)$, bicarbonatadas mistas ou mistas cálcicas $\left(\mathrm{HCO}_{3}^{-}\right.$- mistas ou mistas - $\left.\mathrm{Ca}^{2+}\right)$ $(12 \%)$, cloretadas cálcicas $\left(\mathrm{Cl}^{-}-\mathrm{Ca}^{2+}\right)(16 \%) \mathrm{e}$ fácies bicarbonatadas sódicas $\left(\mathrm{HCO}_{3}-\mathrm{Na}^{+}\right)$ (8\%) (Figura 3). A incerteza do balanço iônico relação à razão do padrão internacional dos isótopos estáveis da molécula da água $\left(\delta^{18} \mathrm{O}\right.$, $\left.\delta^{2} \mathrm{H}\right)(\mathrm{V}-\mathrm{SMOW})$, na notação de delta $(\delta)$ por mil (\%), com uma incerteza admitida de 0,05\%, como apresenta a Equação 1 .

$$
\delta(\% 0)=\left[\frac{R_{\text {amostra }}}{R_{\text {padrão }}}-1\right] X 1000 \text { Eq. (1) }
$$

classificar as amostras hierarquicamente em grupos, admitindo todas as variáveis determinadas para cada indivíduo (Landim, 2011). Foi escolhida a distância Euclidiana como medida de distância ou similaridade entre os pontos amostrais, junto ao método de Ward, para a realização da análise da ligação entre os grupos.

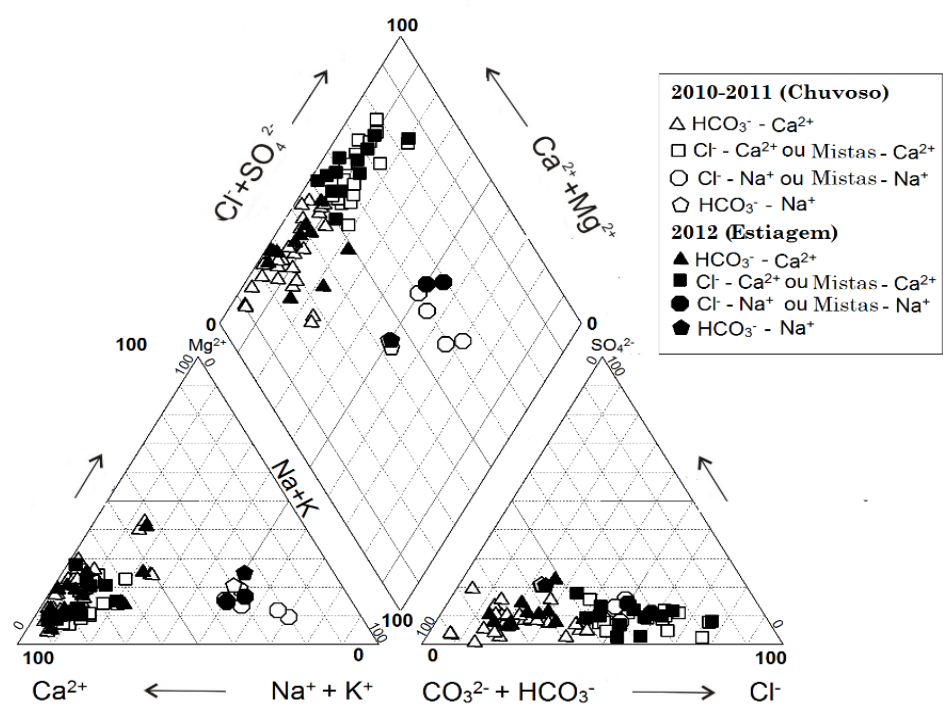

Figura 3 
Verifica-se que as fácies hidroquímicas bicarbonatadas cálcicas, ou mistas cálcicas foram as mais representativas $\left(\mathrm{HCO}_{3}{ }^{-}-\mathrm{Ca}^{2+}\right.$, $\mathrm{HCO}_{3}^{-}$- mistas e mistas - $\left.\mathrm{Ca}^{2+}\right)(78 \%)$ (Figura 3 ), aspecto que pode ser relacionado ao intemperismo químico das fases minerais dolomita e calcita na interação água-rocha. Em relação as fácies cloretadas cálcicas $\left(\mathrm{Cl}^{-}-\mathrm{Ca}^{2+}\right)$ $(16 \%)$, foram associadas a influência do clima, variando com a sazonalidade, e a circulação da água no Aquífero Bambuí. Enquanto que as fácies hidroquímicas bicarbonatadas sódicas ou mistas sódicas $\left(\mathrm{HCO}_{3}-\mathrm{Na}^{+}\right.$, Mistas $\left.-\mathrm{Na}^{+}\right)$ (8\%) talvez estejam relacionadas ao intemperismo químico dos plagioclásios que constituem os pelitos da Formação Serra de Santa Helena, o qual atuaria em consórcio com as reações de troca de bases.

Foi aplicada a técnica de análise de agrupamento para a classificação das amostras em grupos, ou tipos hidroquímicos, com auxílio da observação visual do dendrograma, e associação com as fácies hidroquímicas (Figura 4). Nestes a linha de corte marcada, relativa as campanhas amostrais, ressaltam a distância Euclidiana de 15 nas amostras de 2010 e uma distância 20 nas amostras de 2011 e 2012. Amostras situadas abaixo desta linha pertencem à mesma categoria, marcadas como G1, G2, G3 e G4.

As diferenças na mineralização ou na variação das concentrações dos íons $\mathrm{Cl}^{-}, \mathrm{Na}^{+} \mathrm{e}$ $\mathrm{Ca}^{2+}$, explicaram a formação dos grupos (Tabelas 1 e 2). A classificação destes grupos também contou com a análise dos índices de saturação modelizados e das razões geoquímicas $\mathrm{rCl}^{-} /\left(\mathrm{rCl}^{-}+\mathrm{rHCO}_{3}^{-}\right)$e $\mathrm{rHCO}_{3} / \mathrm{rCa}^{2+}$ (Figura 4). Foi proposto que a adição dos íons $\mathrm{Ca}^{2+}$ decorreria da interação água-rocha, e o acréscimo dos íons $\mathrm{Cl}^{-}$pela circulação da água de chuva no aquífero, condições de recarga e clima. Obteve-se valores da razão $\mathrm{rHCO}_{3}{ }^{-} / \mathrm{rCa}^{2+}$ inferiores a 1,5 para a maior parte das amostras (89\%). Roisenberg et al. (2003) explicaram que amostras de águas com valor da razão $\mathrm{rHCO}_{3}{ }^{-}$ $/ \mathrm{rCa}^{2+}$ inferior a 1,5 pode decorrer $\mathrm{da}$ dissolução da calcita e dolomita ou da subsaturação da solução nesses minerais.

A Figura 5 mostra a distribuição das frequências dos índices modelizados de saturação (IS) dos minerais, cujas amostras foram classificadas segundo as condições de saturação: subsaturada (IS $<-0,5)$, em equilíbrio químico com a solução $(-0,5<$ IS $<$ 0,5 ), ou supersaturada (IS $>0,5$ ). Em relação a calcita, os valores do IS Calcita abrangeram as condições de equilíbrio com a solução e supersaturação e os valores do IS Dolomita contemplaram a subsaturação, equilíbrio com a solução e supersaturação. Observa-se mudanças sazonais nas condições de saturação das fases minerais calcita e dolomita, e destacaram-se as condições de subsaturação da fluorita (96\% das amostras) e subsaturação da gipsita.

A análise e a interpretação dos dados hidroquímicos obtidos permitiram inferir que parte das amostras dos grupos G2 a-b ou G3c $\left(\mathrm{HCO}_{3}^{-}-\mathrm{Ca}^{2+}\right.$ e Mistas $\left.-\mathrm{Ca}^{2+}\right)$ (Figura 4) se situariam sob a influência de zonas de recarga meteórica do aquífero, com menor tempo de trânsito. Os teores iônicos, razões geoquímicas e fácies hidroquímicas nos Grupos G4a, G3b e $\mathrm{G} 4 \mathrm{c}\left(\mathrm{Cl}^{-}-\mathrm{Ca}^{2+}\right)$ podem ser explicados pela influência do clima e da circulação da água nas unidades aquíferas e pela interação água-rocha, mostrando-se concordante com o aumento na aridez na direção do rio São Francisco.

A ocorrência do flúor nas águas subterrâneas de Serra do Ramalho (Tabelas 1 e 2) foram relacionadas, em especial, a presença de fluorita disseminada nas litofácies pelíticas e carbonáticas do Grupo Bambuí. Esclarece-se que o setor agrícola neste município não representa um desenvolvimento significativo, sendo pouco provável a contribuição dos agroquímicos como fonte adicional de fluoreto. Velásquez et al. (2006) e Costa (2011) investigaram a origem e ocorrência de níveis naturais e tóxicos de fluoreto no Aquífero Bambuí, associados às litofácies do Grupo Bambuí, no Norte de Minas Gerais. Gonçalves (2014), Cruz et al. (2015), Gonçalves et al. (2019a) e Gonçalves et al. (2020) investigaram a distribuição dos níveis tóxicos do flúor nas águas do Aquífero Bambuí, no Oeste da Bahia.

A Figura 6 apresenta o Diagrama de Gibbs (1970) e as indicações das fácies hidroquímicas, reportando-se aos principais processos que controlam a evolução geoquímica das águas subterrâneas. As amostras de água subterrâneas do município de Serra do Ramalho se situaram no setor referente aos processos de interação águarocha, o que destaca a relevância da carstificação à hidrogeoquímica. 


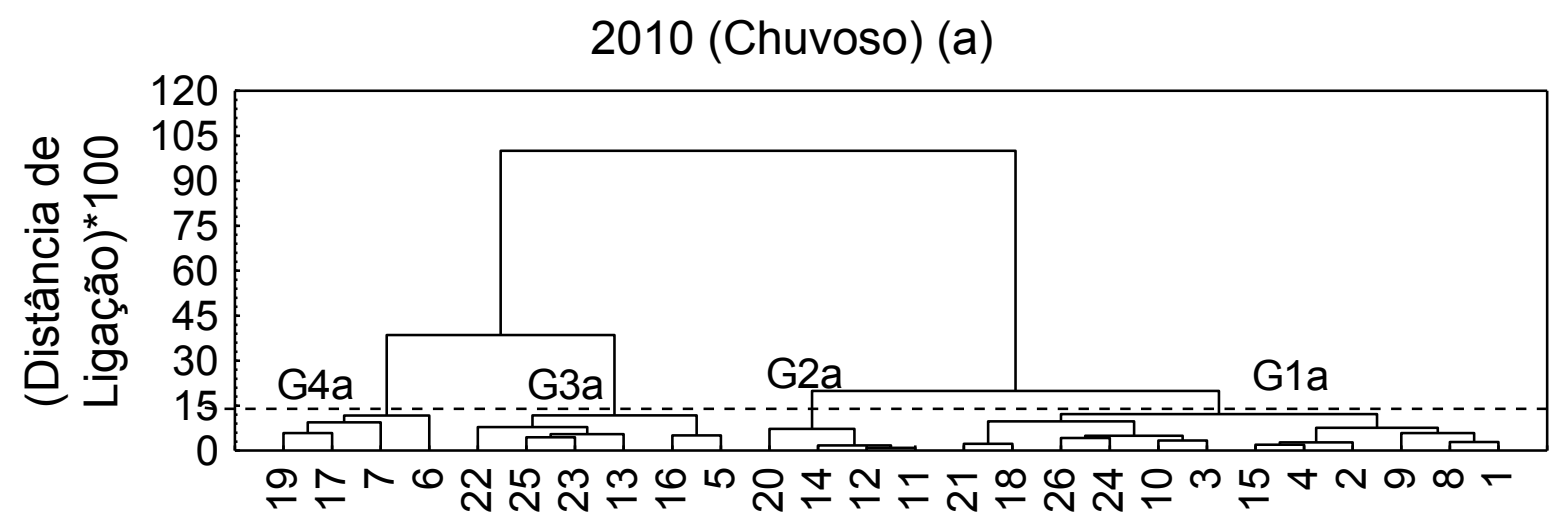

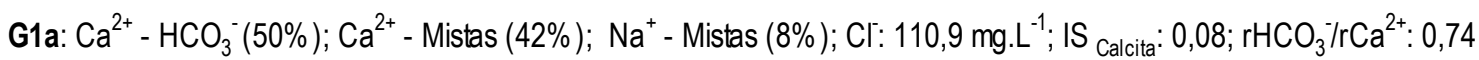
G2a: $\mathrm{Ca}^{2+}-\mathrm{HCO}_{3}^{-}(100 \%) ; \mathrm{Cl}^{-}: 18,10 \mathrm{mg} \cdot \mathrm{L}^{-1} ; \mathrm{IS}_{\text {Calcita }}: 0,25 ; \mathrm{rHCO}_{3}^{-} / \mathrm{rCa}^{2+}: 0,86$

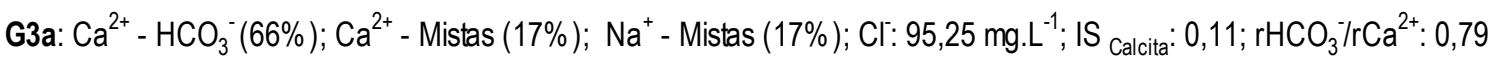
G4a: $\mathrm{Ca}^{2+}-\mathrm{Cl}(100 \%) ; \mathrm{Cl}^{-}: 423,00 \mathrm{mg} \cdot \mathrm{L}^{-1} ; \mathrm{IS}_{\text {Calcita: }}:-0,12 ; \mathrm{rHCO}_{3}^{-} / \mathrm{rCa}^{2+}: 0,46$

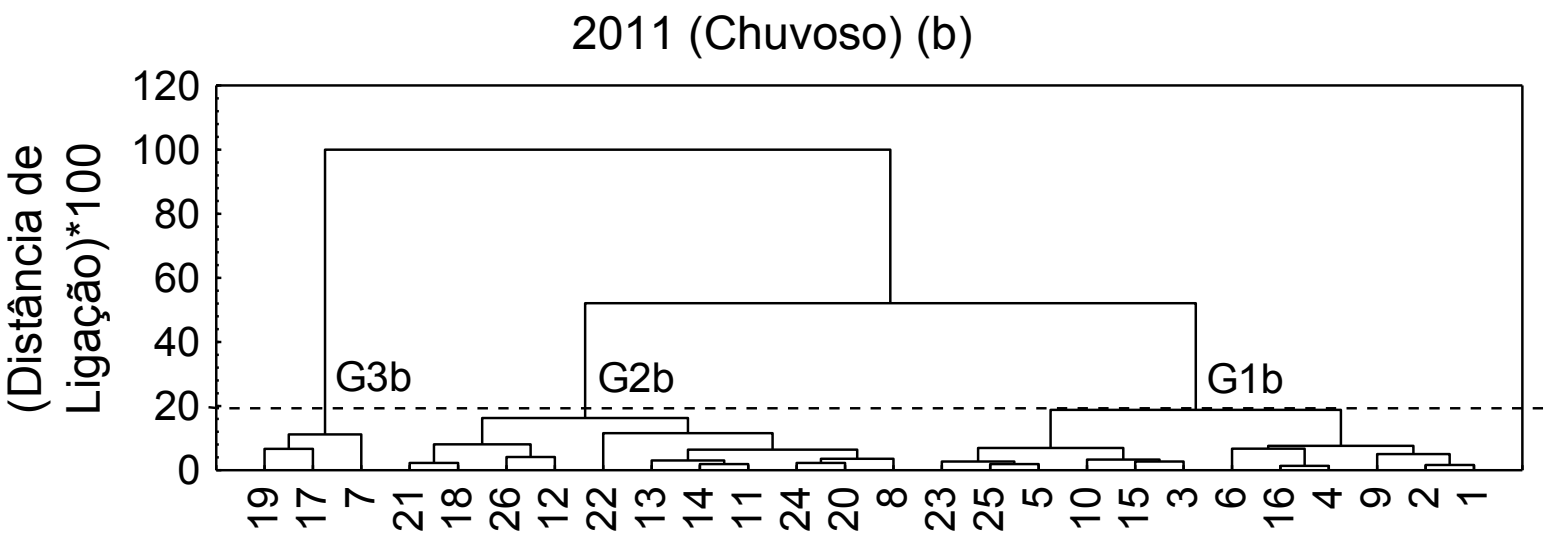

G1b: $\mathrm{Ca}^{2+}-\mathrm{HCO}_{3}^{-}(75 \%) ; \mathrm{Ca}^{2+}-\operatorname{Mistas}(17 \%) ; \mathrm{Ca}^{2+}-\mathrm{Cl}(8 \%) ; \mathrm{Cl}^{-}: 132,00 \mathrm{mg} \cdot \mathrm{L}^{-1} ; \mathrm{IS}_{\text {Calcita: }}: 0,66 ; \mathrm{rHCO}_{3}{ }^{-1} / \mathrm{rCa}^{2+}: 0,69$

G2b: $\mathrm{Ca}^{2+}-\mathrm{HCO}_{3}^{-}(82 \%) ; \mathrm{Na}^{+}-$Mistas (18\%); Cl: $35,00 \mathrm{mg}^{-\mathrm{L}^{-1}} ; \mathrm{IS}_{\text {Calcita }}: 0,75 ; \mathrm{rHCO}_{3}^{-1} / \mathrm{rCa}^{2+}: 0,99$

G3b: $\mathrm{Ca}^{2+}-\mathrm{Cl}(100 \%) ; \mathrm{Cl}: 320,43 \mathrm{mg} \cdot \mathrm{L}^{-1} ; \mathrm{IS}_{\text {Calcita }}: 0,76 ; \mathrm{rHCO}_{3}^{-1} / \mathrm{rCa}^{2+}: 0,39$

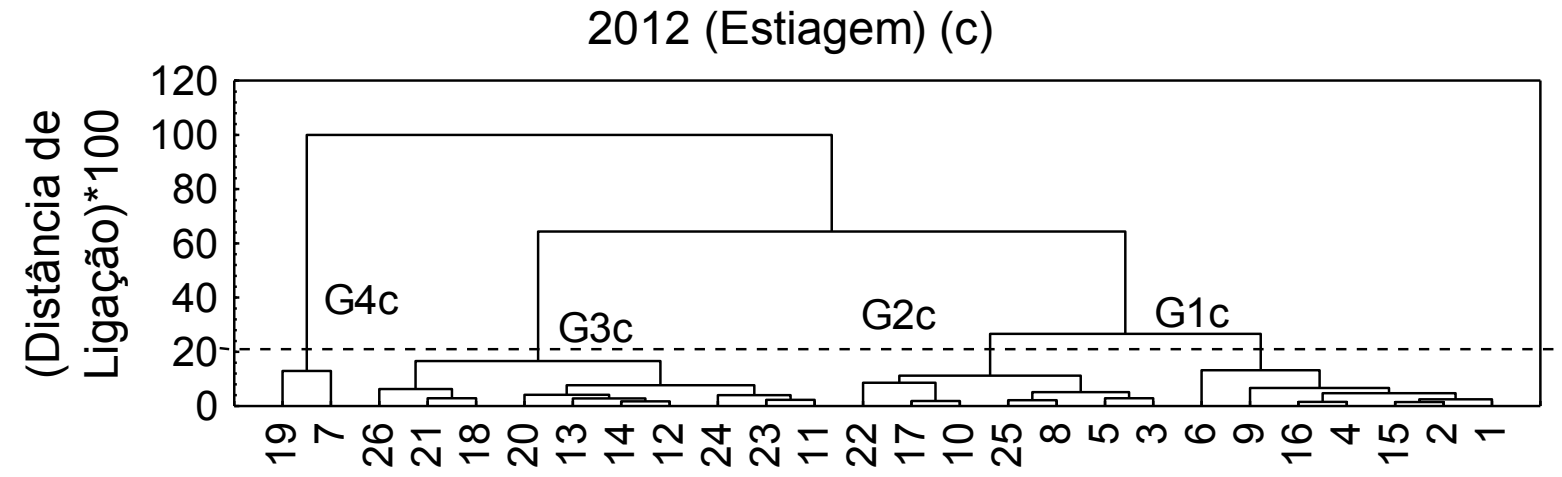

G1c: $\mathrm{Ca}^{2+}-\mathrm{Cl}(57 \%) ; \mathrm{Ca}^{2+}-$ Mistas (29\%); $\mathrm{Ca}^{2+}-\mathrm{HCO}_{3}^{-}(14 \%)$; Cl: $146,90 \mathrm{mg}^{-1}{ }^{-1} ; \mathrm{IS}_{\text {Calcita: }}: 0,5 ; \mathrm{rHCO}_{3}{ }^{-1} \mathrm{rCa}^{2+}: 0,5$ G2C: $\mathrm{Ca}^{2+}-\mathrm{Cr}(43 \%) ; \mathrm{Ca}^{2+}-\mathrm{HCO}_{3}^{-}(43 \%) ; \mathrm{Ca}^{2+}-\operatorname{Mistas}(14 \%) ; \mathrm{Cl}: 95,60 \mathrm{mg} \cdot \mathrm{L}^{-1} ; \mathrm{IS}_{\text {Calcita }}: 0,38 ; \mathrm{rHCO}_{3}^{-} / \mathrm{rCa}^{2+}: 0,64$

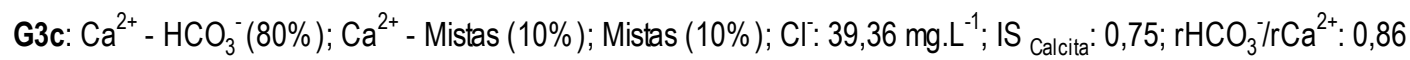
G4C: $\mathrm{Ca}^{2+}-\mathrm{Cr}(100 \%) ; \mathrm{Cl}: 453,95 \mathrm{mg} . \mathrm{L}^{-1} ; \mathrm{IS}_{\text {Calcita }}: 1,0 ; \mathrm{rHCO}_{3} / \mathrm{rCa}^{2+}: 0,36$ 
Tabela 1 - Caracterização hidroquímica das amostras coletadas no período chuvoso (2010 e 2011).

\begin{tabular}{|c|c|c|c|c|c|c|c|c|c|c|c|c|c|c|c|}
\hline \multirow{2}{*}{ Poços } & \multirow[b]{2}{*}{ Fácies } & \multirow[b]{2}{*}{ pH } & \multicolumn{8}{|c|}{ mg.L $\mathbf{L}^{-1}$} & \multirow{2}{*}{$\begin{array}{c}\mathrm{rHCO}_{3}{ }^{-} \\
/ \mathrm{rCa}^{2+}\end{array}$} & \multirow{2}{*}{$\begin{array}{c}\mathrm{rCl}^{-} / \\
\mathrm{rCl}_{+}^{-} \\
\left.\mathrm{HCO}_{3}^{-}\right)^{-} \\
\end{array}$} & \multirow{2}{*}{$\begin{array}{c}\text { IS } \\
\text { Calcita }\end{array}$} & IS & IS \\
\hline & & & STD & $\mathrm{Na}^{+}$ & $\mathbf{K}^{+}$ & $\mathrm{Ca}^{2+}$ & $\mathrm{Mg}^{2+}$ & $\mathrm{HCO}_{3}^{-}$ & $\mathrm{Cl}^{-}$ & $\mathbf{F}^{-}$ & & & & Dolomita & Fluorita \\
\hline Camp: & anha Amostral d & e 2010 & : Grupo & a (G1a) & & & & & & & & & & & \\
\hline P01 & $\mathrm{HCO}_{3}^{-}-\mathrm{Ca}^{2+}$ & 6,90 & 322,70 & 10,00 & 0,93 & 159,39 & 11,13 & 312,72 & 116,80 & 0,34 & 0,64 & 0,39 & 0,11 & $-0,56$ & $-1,69$ \\
\hline P08 & $\mathrm{HCO}_{3}^{-}-\mathrm{Ca}^{2+}$ & 7,10 & 291,80 & 17,60 & 2,53 & 132,45 & 25,74 & 340,56 & 70,00 & 0,20 & 0,84 & 0,26 & 0,26 & 0,20 & $-2,25$ \\
\hline P09 & Mistas $-\mathrm{Ca}^{2+}$ & 8,10 & 368,60 & 38,88 & 3,59 & 113,19 & 26,73 & 330,50 & 182,00 & 0,48 & 0,96 & 0,49 & 1,14 & 2,02 & $-1,57$ \\
\hline $\mathrm{P} 02$ & $\mathrm{HCO}_{3}{ }^{-}-\mathrm{Ca}^{2+}$ & 6,80 & 334,90 & 27,12 & 2,69 & 148,01 & 13,01 & 252,95 & 125,00 & 0,65 & 0,56 & 0,46 & $-0,13$ & $-0,94$ & $-1,22$ \\
\hline $\mathrm{P} 04$ & Mistas - $\mathrm{Ca}^{2+}$ & 7,00 & 331,20 & 31,52 & 3,48 & 144,45 & 12,00 & 188,49 & 117,00 & 0,35 & 0,43 & 0,52 & $-0,04$ & $-0,77$ & $-1,70$ \\
\hline P15 & Mistas $-\mathrm{Ca}^{2+}$ & 6,90 & 353,00 & 16,43 & 1,74 & 116,28 & 19,55 & 202,36 & 138,00 & 0,27 & 0,57 & 0,54 & $-0,20$ & $-0,80$ & $-2,02$ \\
\hline $\mathrm{P} 03$ & $\mathrm{HCO}_{3}^{-}-\mathrm{Ca}^{2+}$ & 7,00 & 272,30 & 12,00 & 0,79 & 146,70 & 5,81 & 231,60 & 28,90 & 0,24 & 0,52 & 0,18 & 0,08 & $-0,85$ & $-1,99$ \\
\hline $\mathrm{P} 10$ & Mistas $-\mathrm{Ca}^{2+}$ & 7,00 & 270,80 & 16,24 & 2,18 & 114,27 & 6,02 & 204,08 & 120,00 & 0,21 & 0,59 & 0,50 & $-0,08$ & $-1,05$ & $-2,22$ \\
\hline $\mathrm{P} 24$ & $\mathrm{HCO}_{3}^{-}-\mathrm{Ca}^{2+}$ & 7,10 & 253,70 & 35,08 & 2,10 & 65,62 & 18,98 & 281,98 & 29,40 & 2,15 & 1,41 & 0,15 & $-0,04$ & $-0,20$ & $-0,48$ \\
\hline $\mathrm{P} 18$ & Mistas - $\mathrm{Na}^{+}$ & 7,70 & 342,80 & 35,00 & 18,20 & 10,70 & 2,20 & 164,58 & 105,00 & 0,74 & 1,38 & 0,52 & 0,08 & $-0,02$ & $-1,57$ \\
\hline $\mathrm{P} 21$ & $\mathrm{HCO}_{3}^{-}-\mathrm{Ca}^{2+}$ & 7,90 & 341,60 & 77,52 & 3,14 & 39,11 & 10,41 & 183,93 & 42,50 & 0,74 & 2,01 & 0,28 & 0,23 & 0,47 & $-1,69$ \\
\hline P26 & $\mathrm{HCO}_{3}^{-} \mathrm{Ca}^{2+}$ & 7,70 & 314,31 & 60,72 & 1,48 & 29,97 & 12,10 & 241,00 & 35,00 & 1,76 & 2,26 & 0,20 & 0,19 & 0,84 & 0,43 \\
\hline & Mediana & 7,05 & 326,95 & 29,32 & 2,355 & 115,275 & 12,05 & 236,3 & 110,9 & 0,42 & 0,74 & 0,425 & $\mathbf{0 , 0 8}$ & $-\mathbf{0 , 3 8}$ & $-1,69$ \\
\hline Grupo & $2 a(G 2 a)$ & & & & & & & & & & & & & & \\
\hline P11 & $\mathrm{HCO}_{3}^{-}-\mathrm{Ca}^{2+}$ & 6,90 & 390,30 & 4,56 & 1,02 & 100,33 & 9,08 & 275,41 & 10,40 & 0,14 & 0,90 & 0,06 & $-0,10$ & $-0,86$ & $-2,59$ \\
\hline $\mathrm{P} 12$ & $\mathrm{HCO}_{3}^{-}-\mathrm{Ca}^{2+}$ & 7,30 & 385,30 & 3,36 & 2,19 & 105,89 & 19,44 & 256,60 & 25,00 & 0,22 & 0,79 & 0,14 & 0,28 & 0,20 & $-2,20$ \\
\hline $\mathrm{P} 14$ & $\mathrm{HCO}_{3}^{-}-\mathrm{Ca}^{2+}$ & 7,40 & 388,80 & 7,76 & 0,88 & 93,10 & 7,94 & 231,19 & 38,90 & 0,18 & 0,81 & 0,22 & 0,28 & $-0,14$ & $-2,39$ \\
\hline $\mathrm{P} 20$ & $\mathrm{HCO}_{3}^{-}-\mathrm{Ca}^{2+}$ & 7,10 & 425,50 & 13,52 & 2,43 & 109,25 & 16,75 & 378,85 & 11,20 & 0,87 & 1,14 & 0,05 & 0,21 & $-0,02$ & $-1,03$ \\
\hline & Mediana & 7,20 & 389,55 & 6,16 & 1,61 & 103,11 & 12,92 & 266,01 & 18,10 & $\mathbf{0 , 2 0}$ & 0,86 & $\mathbf{0 , 1 0}$ & 0,25 & $-0,08$ & $-2,30$ \\
\hline Grupo & 3a (G3a) & & & & & & & & & & & & & & \\
\hline P05 & $\mathrm{HCO}_{3}^{-}-\mathrm{Ca}^{2+}$ & 7,00 & 593,90 & 3,40 & 2,00 & 126,80 & 33,20 & 337,60 & 94,60 & 0,60 & 0,87 & 0,33 & 0,13 & 0,05 & $-1,34$ \\
\hline P16 & Mistas - $\mathrm{Ca}^{2+}$ & 6,90 & 611,90 & 26,16 & 2,13 & 121,96 & 10,81 & 205,36 & 141,00 & 0,61 & 0,55 & 0,54 & $-0,16$ & $-0,98$ & $-1,30$ \\
\hline P13 & $\mathrm{HCO}_{3}{ }^{-}-\mathrm{Ca}^{2+}$ & 7,50 & 467,70 & 3,28 & 1,10 & 118,48 & 15,82 & 181,97 & 23,70 & 0,11 & 0,50 & 0,18 & 0,38 & 0,27 & $-2,74$ \\
\hline $\mathrm{P} 23$ & $\mathrm{HCO}_{3}^{-}-\mathrm{Ca}^{2+}$ & 6,80 & 508,60 & 7,84 & 0,90 & 118,88 & 23,39 & 341,11 & 13,30 & 1,90 & 0,94 & 0,06 & $-0,06$ & $-0,46$ & $-0,49$ \\
\hline $\mathrm{P} 25$ & $\mathrm{HCO}_{3}^{-}-\mathrm{Ca}^{2+}$ & 7,10 & 523,50 & 13,42 & 1,65 & 110,19 & 16,20 & 240,26 & 95,90 & 0,32 & 0,71 & 0,41 & 0,08 & $-0,28$ & $-1,89$ \\
\hline $\mathrm{P} 22$ & $\mathrm{HCO}_{3}^{-}-\mathrm{Na}^{+}$ & 8,10 & 513,70 & 111,04 & 2,05 & 27,86 & 8,01 & 145,66 & 114,60 & 1,15 & 1,71 & 0,58 & 0,26 & 0,35 & $-1,32$ \\
\hline & Mediana & 7,05 & $\mathbf{5 1 8 , 6 0}$ & 10,63 & $\mathbf{1 , 8 3}$ & 118,68 & 16,01 & 222,81 & 95,25 & 0,61 & 0,79 & $\mathbf{0 , 3 7}$ & 0,11 & $-0,12$ & $-1,33$ \\
\hline Grupo & $4 a(G 4 a)$ & & & & & & & & & & & & & & \\
\hline P06 & $\mathrm{Cl}^{-}-\mathrm{Ca}^{2+}$ & 6,60 & 478,10 & 27,52 & 2,15 & 190,20 & 18,96 & 261,31 & 323,00 & 0,40 & 0,45 & 0,68 & $-0,21$ & $-1,02$ & $-1,66$ \\
\hline P07 & $\mathrm{Cl}^{-}-\mathrm{Ca}^{2+}$ & 6,70 & 585,70 & 62,40 & 4,06 & 178,20 & 23,28 & 250,60 & 656,00 & 0,51 & 0,46 & 0,82 & $-0,21$ & $-0,92$ & $-1,48$ \\
\hline P17 & $\mathrm{Cl}^{-}-\mathrm{Ca}^{2+}$ & 6,90 & 638,30 & 16,80 & 2,20 & 166,26 & 12,17 & 235,19 & 485,00 & 0,29 & 0,46 & 0,78 & $-0,02$ & $-0,80$ & $-1,86$ \\
\hline P19 & $\mathrm{Cl}^{-}-\mathrm{Ca}^{2+}$ & 7,20 & 584,90 & 32,81 & 3,32 & 194,45 & 43,75 & 224,47 & 361,00 & 0,91 & 0,38 & 0,73 & 0,33 & 0,42 & $-0,90$ \\
\hline & Mediana & 6,80 & 585,30 & 30,17 & 2,76 & 184,20 & 21,12 & 242,90 & 423,00 & 0,46 & 0,46 & 0,76 & $-0,12$ & $-0,86$ & $-1,57$ \\
\hline Camp: & anha Amostral c & e 2011 & : Grupo & b (G1b) & & & & & & & & & & & \\
\hline $\mathrm{P} 01$ & $\mathrm{HCO}_{3}^{-}-\mathrm{Ca}^{2+}$ & 7,70 & 606,00 & 155,55 & 8,46 & 6,50 & 0,68 & 302,49 & 132,00 & 0,31 & 0,64 & 0,43 & 0,90 & 0,92 & $-1,79$ \\
\hline P02 & $\mathrm{HCO}_{3}^{-}-\mathrm{Ca}^{2+}$ & 7,40 & 635,70 & 135,65 & 9,79 & 13,62 & 2,09 & 273,73 & 132,00 & 0,79 & 0,66 & 0,45 & 0,50 & 0,24 & $-1,01$ \\
\hline P04 & $\mathrm{HCO}_{3}^{-}-\mathrm{Ca}^{2+}$ & 7,00 & 663,00 & 114,18 & 21,77 & 22,48 & 3,20 & 198,85 & 139,35 & 0,36 & 0,47 & 0,55 & $-0,03$ & $-0,81$ & $-1,71$ \\
\hline P09 & $\mathrm{HCO}_{3}^{-}-\mathrm{Ca}^{2+}$ & 7,60 & 721,50 & 137,64 & 9,74 & 24,70 & 2,54 & 301,25 & 125,00 & 0,48 & 0,87 & 0,42 & 0,64 & 0,94 & $-1,53$ \\
\hline P16 & $\mathrm{HCO}_{3}^{-}$-Mistas & 7,80 & 624,00 & 142,88 & 10,68 & 12,80 & 1,90 & 189,95 & 143,69 & 0,55 & 0,44 & 0,57 & 0,75 & 0,76 & $-1,31$ \\
\hline P06 & $\mathrm{Cl}^{-}-\mathrm{Ca}^{2+}$ & 7,13 & 671,50 & 188,25 & 16,41 & 20,71 & 1,96 & 251,55 & 251,00 & 0,37 & 0,44 & 0,63 & 0,31 & $-0,04$ & $-1,61$ \\
\hline $\mathrm{P} 03$ & $\mathrm{HCO}_{3}^{-}-\mathrm{Ca}^{2+}$ & 7,80 & 532,00 & 132,98 & 4,01 & 10,06 & 0,65 & 290,00 & 80,00 & 0,27 & 0,72 & 0,32 & 0,92 & 0,71 & $-1,94$ \\
\hline $\mathrm{P} 15$ & $\mathrm{HCO}_{3}^{-}-\mathrm{Ca}^{2+}$ & 7,60 & 544,70 & 119,17 & 28,58 & 15,81 & 2,48 & 300,11 & 140,00 & 0,29 & 0,83 & 0,45 & 0,67 & 1,11 & $-1,99$ \\
\hline P10 & Mistas $-\mathrm{Ca}^{2+}$ & 7,40 & 505,00 & 121,11 & 6,51 & 13,84 & 1,79 & 241,11 & 145,00 & 0,18 & 0,65 & 0,51 & 0,40 & $-0,07$ & $-2,33$ \\
\hline P05 & $\mathrm{HCO} 3-\mathrm{Ca}^{2+}$ & 7,00 & 584,80 & 126,80 & 33,20 & 3,40 & 2,00 & 337,60 & 94,60 & 0,40 & 0,87 & 0,33 & 0,14 & 0,08 & $-1,70$ \\
\hline P25 & $\mathrm{HCO}_{3}^{-}-\mathrm{Ca}^{2+}$ & 7,90 & 568,10 & 115,49 & 15,39 & 17,95 & 1,42 & 344,00 & 80,00 & 0,35 & 0,98 & 0,29 & 1,02 & 1,57 & $-1,82$ \\
\hline $\mathrm{P} 23$ & $\mathrm{HCO}_{3}^{-}-\mathrm{Ca}^{2+}$ & 7,70 & 525,00 & 120,22 & 22,74 & 9,40 & 1,24 & 364,59 & 50,00 & 1,51 & 0,99 & 0,19 & 0,88 & 1,44 & $-0,55$ \\
\hline & Mediana & 7,60 & $\mathbf{5 9 5 , 4 0}$ & 29,89 & 13,04 & 13,73 & 1,93 & 295,06 & 132,00 & $\mathbf{0 , 3 7}$ & 0,69 & 0,44 & 0,66 & 0,74 & $-1,71$ \\
\hline Grupo & $2 b(G 2 b)$ & & & & & & & & & & & & & & \\
\hline P08 & $\mathrm{HCO}_{3}{ }^{-}-\mathrm{Ca}^{2+}$ & 7,50 & 439,40 & 130,18 & 22,75 & 13,20 & 2,33 & 335,83 & 75,14 & 0,26 & 0,85 & 0,28 & 0,65 & 0,93 & $-2,02$ \\
\hline $\mathrm{P} 20$ & $\mathrm{HCO}_{3}{ }^{-} \mathrm{Ca}^{2+}$ & 7,90 & 449,00 & 101,49 & 12,13 & 15,33 & 1,71 & 306,00 & 35,00 & 0,85 & 0,99 & 0,16 & 0,91 & 1,29 & $-1,06$ \\
\hline $\mathrm{P} 24$ & $\mathrm{HCO}_{3}^{-}-\mathrm{Ca}^{2+}$ & 7,90 & 487,50 & 62,29 & 18,09 & 34,69 & 1,73 & 300,34 & 34,00 & 1,79 & 1,58 & 0,16 & 0,72 & 1,29 & $-0,62$ \\
\hline P11 & $\mathrm{HCO}_{3}{ }^{-} \mathrm{Ca}^{2+}$ & 7,80 & 409,00 & 93,85 & 8,36 & 2,37 & 0,82 & 263,47 & 35,00 & 0,21 & 0,92 & 0,19 & 0,75 & 0,84 & $-2,28$ \\
\hline $\mathrm{P} 14$ & $\mathrm{HCO}_{3}^{-}-\mathrm{Ca}^{2+}$ & 8,10 & 415,00 & 82,28 & 7,21 & 6,31 & 0,75 & 217,12 & 40,00 & 0,19 & 0,87 & 0,24 & 0,91 & 1,14 & $-2,41$ \\
\hline P13 & $\mathrm{HCO}_{3}{ }^{-}-\mathrm{Ca}^{2+}$ & 7,80 & 473,20 & 118,72 & 15,42 & 2,70 & 0,89 & 236,76 & 28,15 & 0,12 & 0,65 & 0,17 & 0,79 & 1,07 & $-2,68$ \\
\hline $\mathrm{P} 22$ & Mistas-Na ${ }^{+}$ & 8,70 & 535,00 & 24,32 & 8,04 & 83,25 & 1,62 & 148,07 & 106,00 & 1,14 & 2,00 & 0,55 & 0,79 & 1,49 & $-1,39$ \\
\hline $\mathrm{P} 12$ & $\mathrm{HCO}_{3}^{-}-\mathrm{Ca}^{2+}$ & 8,20 & 333,00 & 101,33 & 22,66 & 4,29 & 2,73 & 291,28 & 30,00 & 0,23 & 0,94 & 0,15 & 1,17 & 2,06 & $-2,19$ \\
\hline P26 & $\mathrm{HCO}_{3}^{-}-\mathrm{Ca}^{2+}$ & 8,10 & 297,70 & 31,91 & 18,96 & 10,34 & 2,36 & 225,00 & 33,00 & 1,74 & 2,31 & 0,20 & 0,74 & 1,13 & $-1,78$ \\
\hline P18 & Mistas $-\mathrm{Na}^{+}$ & 8,10 & 350,40 & 39,28 & 10,57 & 63,09 & 2,11 & 139,31 & 87,60 & 0,73 & 1,16 & 0,52 & 0,42 & 0,65 & $-1,57$ \\
\hline $\mathrm{P} 21$ & Mistas - $\mathrm{Ca}^{2+}$ & 7,95 & 356,90 & 31,56 & 12,94 & 59,27 & 1,06 & 165,59 & 38,13 & 0,81 & 1,72 & 0,28 & 0,25 & 0,49 & $-1,57$ \\
\hline & Mediana & 7,95 & 415,00 & 82,28 & 12,94 & 13,2 & 1,71 & 236,76 & 35,00 & 0,73 & 0,99 & $\mathbf{0 , 2 0}$ & 0,75 & 1,13 & $-1,78$ \\
\hline Grups & 3b (G3b) & & & & & & & & & & & & & & \\
\hline P07 & $\mathrm{Cl}^{-}-\mathrm{Ca}^{2+}$ & 7,50 & 1170,00 & 196,19 & 24,40 & 51,25 & 4,86 & 355,23 & 460,00 & 0,54 & 0,59 & 0,69 & 0,78 & 1,04 & -1.31 \\
\hline P17 & $\mathrm{Cl}^{-}-\mathrm{Ca}^{2+}$ & 7,50 & 921,00 & 220,50 & 14,10 & 18,27 & 2,56 & 249,68 & 315,00 & 0,28 & 0,37 & 0,68 & 0,70 & 0,58 & -1.76 \\
\hline P19 & $\mathrm{Cl}^{-}-\mathrm{Ca}^{2+}$ & 7,60 & 1080,00 & 205,82 & 40,73 & 32,81 & 2,67 & 245,81 & 320,43 & 0,91 & 0,39 & 0,69 & 0,76 & 1,20 & -0.84 \\
\hline & Mediana & $\mathbf{7 , 5 0}$ & 1080,00 & 205,82 & 24,4 & 32,81 & 2,67 & 249,68 & 320,43 & 0,54 & 0,39 & 0,69 & 0,76 & 1,04 & $-1,31$ \\
\hline
\end{tabular}

P: campanha amostral de novembro de 2010; NV: campanha de novembro de 2011. 
2010-2011 (Chuvoso)

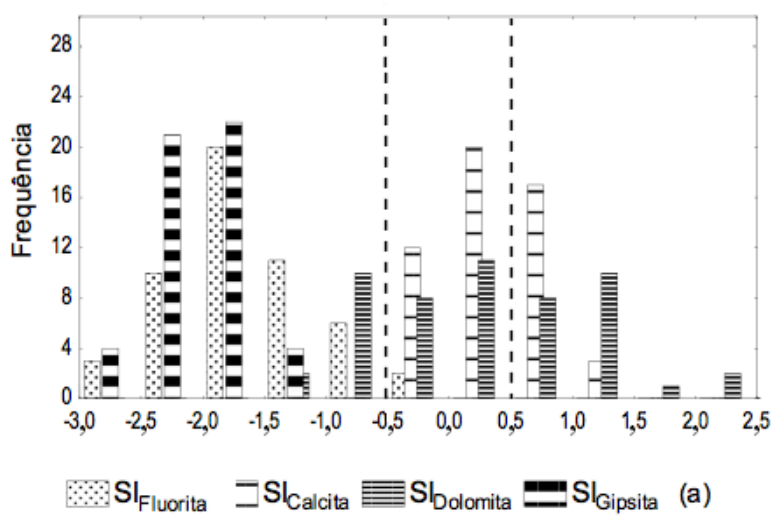

2012 (Estiagem)

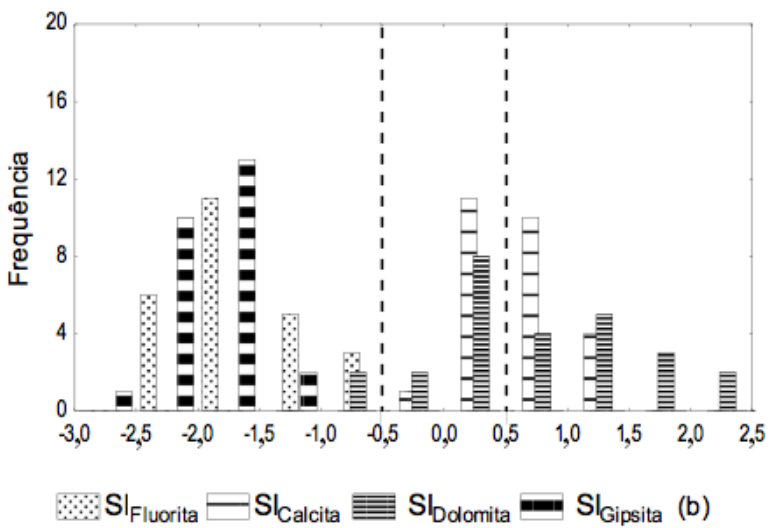

Figure 5

Distribuição das frequências dos índices de saturação dos minerais modelizados.

Tabela 2 - Caracterização hidroquímica das amostras coletadas no período de estiagem (2012).

\begin{tabular}{|c|c|c|c|c|c|c|c|c|c|c|c|c|c|c|c|c|c|}
\hline \multirow{2}{*}{ Poços } & \multicolumn{2}{|c|}{ UTM(m) } & \multirow{2}{*}{ Fácies } & \multirow{2}{*}{ pH } & \multicolumn{8}{|c|}{ mg.. $\mathrm{L}^{-11}$} & \multirow{2}{*}{$\begin{array}{c}\mathrm{rHCO}_{3}{ }^{-} / \\
\mathrm{rCa}^{2+}\end{array}$} & \multirow{2}{*}{$\begin{array}{c}\mathrm{rCC} / \\
\left(\mathrm{rCT}_{+} \mathrm{HCO}_{3}^{-}\right)\end{array}$} & \multicolumn{3}{|c|}{ IS } \\
\hline & $\mathbf{N} / \mathbf{S}$ & $\mathbf{E} / \mathbf{W}$ & & & STD & $\mathrm{Na}^{+}$ & $\mathbf{K}^{+}$ & $\mathrm{Ca}^{2+}$ & $\mathbf{M g}^{2+}$ & $\mathrm{HCO}_{3}^{-}$ & $\mathbf{C r}$ & $\mathbf{F}$ & & & Calcita & Dolomita & Fluonita \\
\hline \multicolumn{18}{|c|}{ Campanha Amostral 2012: Grupo 1 c (G1c) } \\
\hline $\mathrm{P} 01$ & 8503946 & 647135 & $\mathrm{Cl}^{-}-\mathrm{Ca}^{2+}$ & 7,50 & 630,00 & 7,02 & 0,49 & 141,90 & 9,56 & 215,20 & 146,90 & 0,25 & 0,50 & 0,54 & 0,5 & 0,19 & $-1,96$ \\
\hline $\mathrm{P} 02$ & 8510146 & 648306 & Mistas $-\mathrm{Ca}^{2+}$ & 7,50 & 629,20 & 20,19 & 2,00 & 140,70 & 11,96 & 229,20 & 130,60 & 0,55 & 0,53 & 0,50 & 0,51 & 0,32 & $-1,31$ \\
\hline $\mathrm{P} 15$ & 8519500 & 638051 & Mistas- $\mathrm{Ca}^{2+}$ & 7,80 & 632,00 & 15,18 & 1,61 & 120,60 & 23,15 & 224,50 & 125,10 & 0,25 & 0,61 & 0,49 & 0,74 & 1,14 & $-2,07$ \\
\hline $\mathrm{P} 04$ & 8513348 & 657375 & $\mathrm{Cl}-\mathrm{Ca}^{2+}$ & 7,40 & 670,00 & 25,88 & 2,41 & 145,60 & 11,85 & 196,50 & 160,90 & 0,34 & 0,44 & 0,58 & 0,39 & 0,08 & $-1,75$ \\
\hline P16 & 8520678 & 658486 & $\mathrm{Cl}-\mathrm{Ca}^{2+}$ & 7,40 & 649,00 & 18,84 & 2,25 & 146,20 & 11,75 & 180,10 & 168,70 & 0,45 & 0,40 & 0,62 & 0,32 & $-0,07$ & $-1,47$ \\
\hline $\mathrm{P} 09$ & 8511776 & 638061 & Mistas $-\mathrm{Ca}^{2+}$ & 7,20 & 721,50 & 30,32 & 2,88 & 128,70 & 24,89 & 282,00 & 132,40 & 0,42 & 0,72 & 0,45 & 0,26 & 0,18 & $-1,61$ \\
\hline \multirow[t]{2}{*}{ P06 } & 8519500 & 638051 & $\mathrm{Cl}-\mathrm{Ca}^{2+}$ & 7,50 & 819,00 & 26,21 & 1,45 & 171,60 & 16,69 & 206,00 & 252,00 & 0,28 & 0,39 & 0,68 & 0,55 & 0,48 & $-1,88$ \\
\hline & & & Mediana & 7,50 & 649,00 & 20,19 & 2,00 & 141,90 & 11,96 & 215,20 & 146,90 & 0,34 & 0,50 & 0,54 & 0,50 & 0,19 & $-1,75$ \\
\hline \multicolumn{18}{|c|}{ Grupo 2 c (G2c) } \\
\hline $\mathrm{P} 03$ & 8517492 & 650158 & $\mathrm{HCO}_{3}^{-}-\mathrm{Ca}^{2+}$ & 7,30 & 529,00 & 10,67 & 0,64 & 124,10 & 4,56 & 203,80 & 86,84 & 0,22 & 0,54 & 0,42 & 0,25 & -0.56 & $-2,12$ \\
\hline $\mathrm{P} 05$ & 8518463 & 633512 & Mistas- $\mathrm{Ca}^{2+}$ & 7,40 & 559,50 & 3,10 & 1,90 & 121,00 & 29,20 & 237,60 & 95,60 & 0,30 & 0,64 & 0,41 & 0,37 & 0.50 & $-1,94$ \\
\hline P08 & 8518463 & 633512 & $\mathrm{HCO}_{3}^{-}-\mathrm{Ca}^{2+}$ & 8,40 & 587,60 & 11,99 & 2,24 & 127,90 & 19,75 & 297,00 & 85,10 & 0,32 & 0,76 & 0,33 & 1,44 & 2.46 & $-1,86$ \\
\hline $\mathrm{P} 25$ & 8488516 & 646706 & $\mathrm{HCO}_{3}^{-}-\mathrm{Ca}^{2+}$ & 7,49 & 545,80 & 16,00 & 1,55 & 113,00 & 15,80 & 290,00 & 88,00 & 0,34 & 0,84 & 0,34 & 0,55 & 0.65 & $-1,84$ \\
\hline $\mathrm{P} 10$ & 8497329 & 646198 & $\mathrm{Cl}-\mathrm{Ca}^{2+}$ & 7,40 & 522,00 & 10,34 & 0,81 & 137,10 & 9,05 & 196,00 & 139,60 & 0,39 & 0,47 & 0,55 & 0,37 & -0.05 & $-1,62$ \\
\hline $\mathrm{P} 17$ & 8501652 & 654837 & $\mathrm{Cl}^{-}-\mathrm{Ca}^{2+}$ & 7,60 & 500,50 & 6,68 & 1,31 & 135,80 & 7,91 & 192,00 & 165,70 & 0,25 & 0,46 & 0,60 & 0,53 & 0.20 & $-1,98$ \\
\hline \multirow[t]{2}{*}{$\mathrm{P} 22$} & 8514882 & 668407 & Mistas $-\mathrm{Na}^{+}$ & 8,30 & 510,00 & 67,81 & 0,95 & 31,24 & 11,02 & 110,50 & 120,30 & 1,06 & 1,16 & 0,65 & 0,38 & 0.71 & $-1,33$ \\
\hline & & & Mediana & 7,49 & 529,00 & 10,67 & 1,31 & 124,10 & 11,02 & 203,80 & 95,60 & 0,32 & 0,64 & 0,42 & 0,38 & 0,50 & $-1,86$ \\
\hline \multicolumn{18}{|c|}{ Grupo 3 c (G3c) } \\
\hline P11 & 8498531 & 640422 & $\mathrm{HCO}_{3}^{-}-\mathrm{Ca}^{2+}$ & 6,90 & 421,00 & 3,54 & 0,90 & 102,70 & 9,27 & 269,10 & 26,95 & 0,18 & 0,86 & 0,15 & $-0,11$ & -0.88 & $-2,37$ \\
\hline $\mathrm{P} 23$ & 8501950 & 635391 & $\mathrm{HCO}_{3}^{-}-\mathrm{Ca}^{2+}$ & 7,40 & 462,80 & 11,19 & 1,52 & 105,10 & 23,61 & 272,80 & 57,95 & 2,13 & 0,85 & 0,27 & 0,40 & 0.55 & $-0,28$ \\
\hline $\mathrm{P} 24$ & 8528066 & 635024 & $\mathrm{HCO}_{3}^{-}-\mathrm{Ca}^{2+}$ & 7,96 & 485,60 & 30,26 & 1,46 & 63,80 & 18,58 & 228,70 & 40,46 & 1,58 & 1,18 & 0,23 & 0,68 & 1.22 & $-0,72$ \\
\hline $\mathrm{P} 12$ & 8493084 & 632582 & $\mathrm{HCO}_{3}^{-}-\mathrm{Ca}^{2+}$ & 7,60 & 428,40 & 4,18 & 1,79 & 101,90 & 16,65 & 199,80 & 33,32 & 0,21 & 0,64 & 0,22 & 0,45 & 0.49 & $-2,24$ \\
\hline P14 & 8484052 & 636993 & $\mathrm{HCO}_{3}^{-}-\mathrm{Ca}^{2+}$ & 8,60 & 424,00 & 7,11 & 0,85 & 77,20 & 7,03 & 175,00 & 42,71 & 0,24 & 0,74 & 0,30 & 1,22 & 1.77 & $-2,21$ \\
\hline $\mathrm{P} 13$ & 8490157 & 638394 & $\mathrm{HCO}_{3}^{-}-\mathrm{Ca}^{2+}$ & 8,50 & 471,00 & 2,13 & 0,78 & 103,00 & 15,03 & 200,50 & 31,64 & 0,18 & 0,64 & 0,21 & 1,31 & 2.16 & $-2,38$ \\
\hline $\mathrm{P} 20$ & 8494698 & 631290 & $\mathrm{HCO}_{3}^{-}-\mathrm{Ca}^{2+}$ & 8,10 & 444,60 & 41,91 & 0,68 & 103,15 & 13,79 & 138,20 & 39,46 & 0,88 & 0,44 & 0,33 & 0,78 & 1.06 & $-1,01$ \\
\hline P18 & 8507231 & 667992 & Mistas - Mistas & 8,60 & 359,00 & 60,66 & 2,86 & 37,45 & 9,72 & 114,00 & 82,72 & 0,71 & 0,95 & 0,56 & 0,80 & 1.43 & $-1,59$ \\
\hline $\mathrm{P} 21$ & 8522518 & 658507 & $\mathrm{HCO}_{3}{ }^{-}-\mathrm{Ca}^{2+}$ & 8,70 & 371,80 & 62,00 & 2,05 & 27,00 & 16,34 & 146,50 & 39,26 & 0,76 & 1,70 & 0,32 & 0,84 & 1.82 & $-1,68$ \\
\hline \multirow[t]{2}{*}{$\mathrm{P} 26$} & 8490758 & 637601 & $\mathrm{HCO}_{3}^{-}$-Mistas & 7,90 & 307,00 & 11,00 & 1,60 & 30,00 & 17,10 & 207,08 & 24,10 & 1,95 & 2,26 & 0,17 & 0,71 & 1.07 & $-1,61$ \\
\hline & & & Mediana & 8,03 & 426,20 & 11,10 & 1,49 & 89,55 & 15,69 & 200,15 & 39,36 & 0,74 & 0,86 & 0,25 & $\mathbf{0 , 7 5}$ & 1,15 & $-1,65$ \\
\hline \multicolumn{18}{|c|}{ Grupo 4 c (G4c) } \\
\hline & 8529722 & 660575 & $\mathrm{Cl}-\mathrm{Ca}^{2+}$ & 8,10 & 1230,00 & 64,71 & 5,26 & 192,40 & 27,40 & 205,20 & 578,50 & 0,11 & 0,35 & 0,83 & 1,12 & 1.78 & $-1,38$ \\
\hline \multirow[t]{2}{*}{ P19 } & 8524474 & 651877 & $\mathrm{Cl}^{-}-\mathrm{Ca}^{2+}$ & 7,80 & 1118,00 & 30,63 & 2,99 & 196,30 & 34,82 & 221,70 & 329,40 & 0,51 & 0,37 & 0,72 & 0,88 & 1.39 & $-0,67$ \\
\hline & & & Mediana & 7,95 & 1174,00 & 47,67 & 4,13 & 194,35 & 31,11 & 213,45 & 453,95 & 0,31 & 0,36 & 0,78 & 1,00 & 1,59 & $-1,03$ \\
\hline
\end{tabular}

JH: campanha amostral de julho de 2012. 


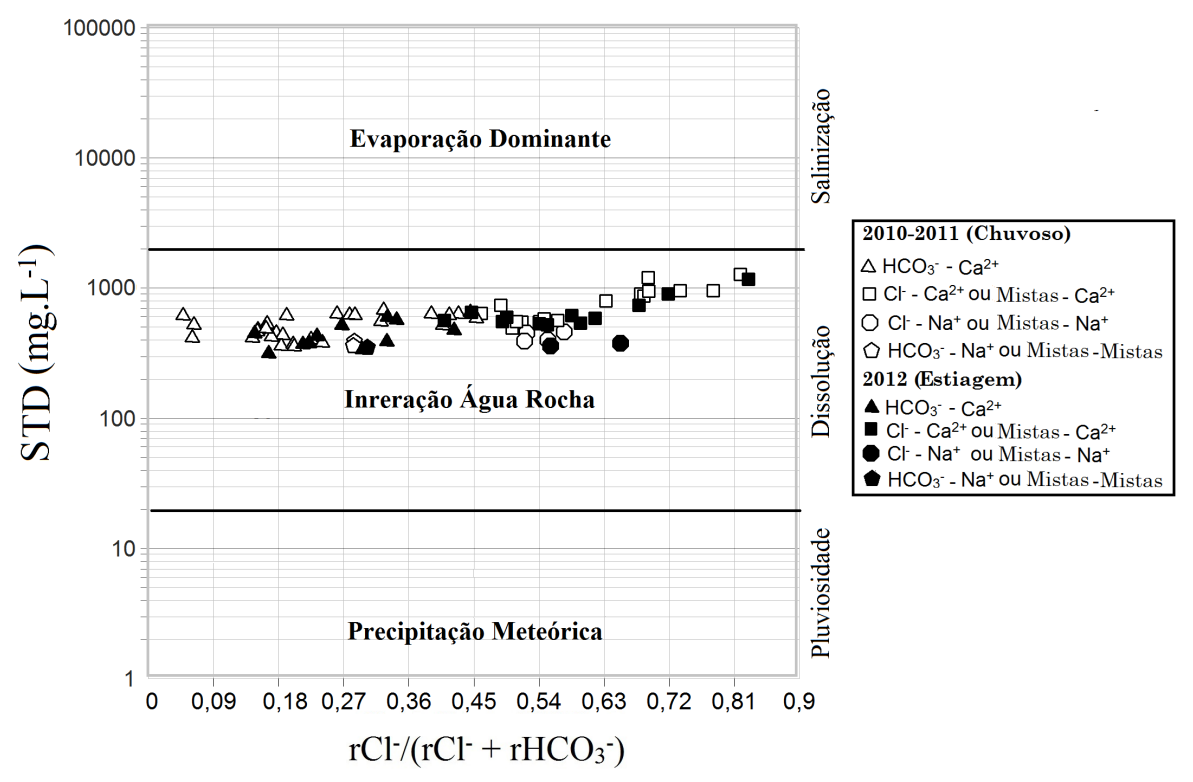

Figura 6

Diagrama de Gibbs (1970) indicando os processos que controlam a hidroquímica.

\subsection{QUALIDADE DAS ÁGUAS E VIGILÂNCIA EM SAÚDE AMBIENTAL}

A Figura 7 aponta as restrições locais quanto aos limites de potabilidade preconizado pela Portaria 2.914/11 (Brasil, 2012), ou pela W.H.O (2006), das variáveis cálcio $(81 \%)$, alumínio $(71 \%)$, nitrato $(40 \%)$, fluoreto $(23 \%)$, cloreto $(13 \%)$, DT $(11 \%)$, STD $(8 \%)$, nitrito $(6 \%)$, bário (15\%), manganês $(4 \%)$ e cádmio (4\%). As condições oxidantes $(92 \%)$ e alcalinas $(77 \%)$ foram dominantes e os teores dos íons cálcio e magnésio das amostras contribuem para a dureza de carbonatos (Tabela 3). A dureza total na água não possui significado sanitário, mas causa inconveniência econômica, porque dificulta a lavagem e o cozimento de alimentos e obstruem as tubulações, a depender do conteúdo de cátions multivalentes em solução na água, especialmente quanto aos íons $\mathrm{Ca}^{2+} \mathrm{e}$ $\mathrm{Mg}^{2+}$ (LIBÂNIO, 2016).

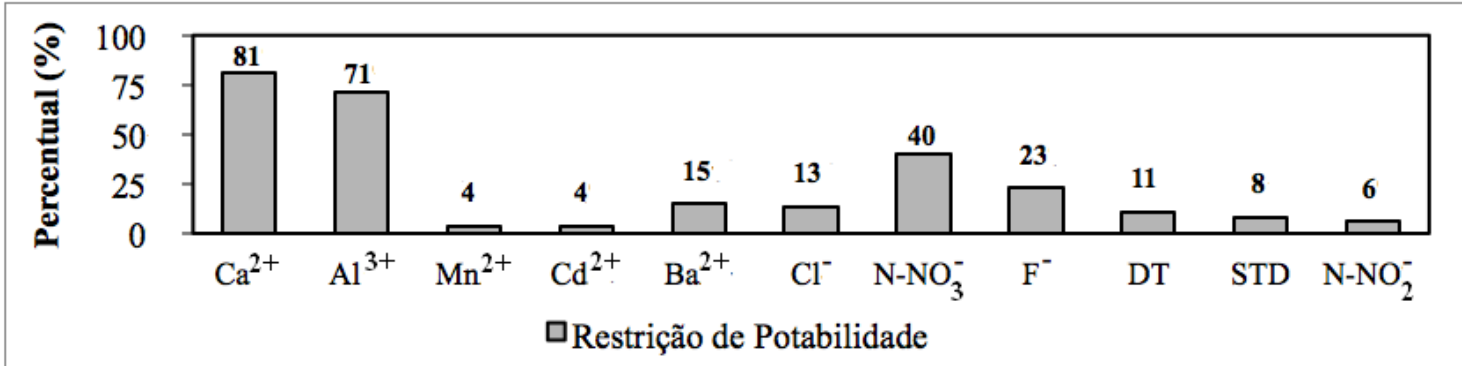

Figura 7

Variáveis hidroquímicas e percentuais de amostras que excederam o limite máximo preconizado pela Portaria 2.914/11 (Brasil, 2012) ou indicado pela W.H.O. (2006).

A aplicação do teste de Kruskal-Wallis apontou, após verificar que a distribuição dos dados segue padrão de distribuição não gaussiana (Tabela 4a-c), não haver diferença sazonal estatística significativa entre as amostras, em relação as medianas das variáveis $\mathrm{Cl}^{-}(p=0,72)$, $\mathrm{SO}_{4}{ }^{2-}(p=0,82), \mathrm{N}^{-} \mathrm{NO}_{3}{ }^{-}(p=0,56), \mathrm{F}^{-}(p=0,83) \mathrm{e}$ DT $(p=0,78)$. Entretanto, as medianas das variáveis $\operatorname{STD}(p=0,001), \mathrm{pH}(p<0,0001)$, ORP $(p<0,0001), \quad \mathrm{HCO}_{3}{ }^{-} \quad(p=0,001) \quad$ e $\quad \mathrm{N}^{-\mathrm{NO}_{2}}{ }^{-}$ $(p<0,0001)$ indicaram variação sazonal.
As concentrações do nitrito se mostraram em desacordo com a Portaria 2.914/11 (BRASIL, 2012) apenas nas amostras de 2010 (Figura 8a), cujos valores desta variável indicaram, no geral, que a poluição da massa de água não poderia ser recente, exceto para aproximadamente $6 \%$ das amostras. As amostras da campanha de 2010, período chuvoso, diferiram das demais, o que talvez decorra do momento da coleta, o que corrobora com a relevância da poluição por efluentes líquidos domésticos. 


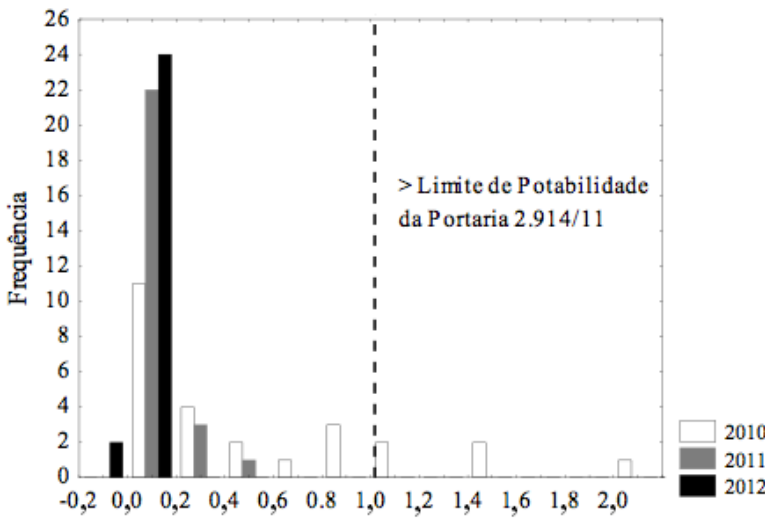

$\mathrm{N}-\mathrm{NO}_{2} \cdot\left(\mathrm{mg} \cdot \mathrm{L}^{-1}\right)$

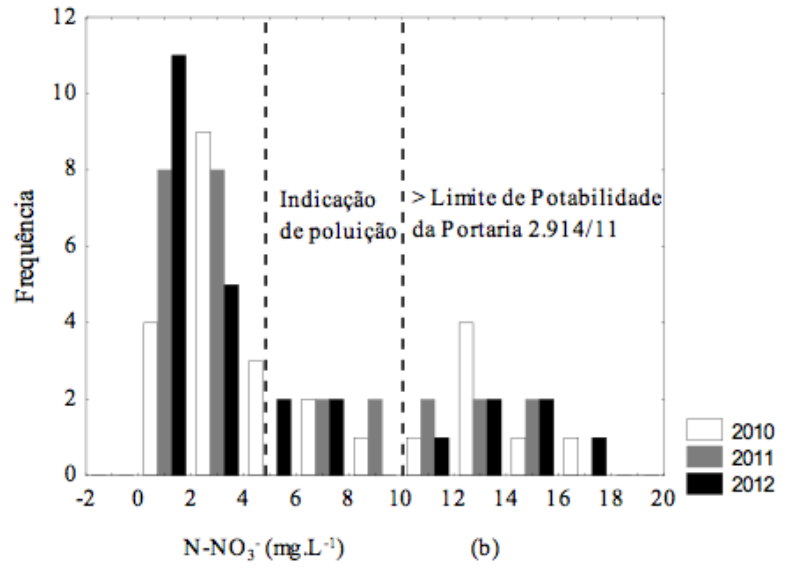

Figura 8

Histograma de distribuição dos teores do nitrato e do nitrito. A. Nitrito $\left(\mathrm{N}-\mathrm{NO}_{2}{ }^{-}\right)$. B. Nitrato $\left(\mathrm{N}-\mathrm{NO}_{3}{ }^{-}\right)$
Os teores do nitrato $\left({\mathrm{N}-\mathrm{NO}_{3}}^{-}\right)$variaram de 0,16 a $15,13 \mathrm{mg} \cdot \mathrm{L}^{-1}$ (Tabela 3 ), de modo que $24 \%$ das amostras estiveram em desacordo com a Portaria 2.914/11 (BRASIL, 2012), e mais $16 \%$ apontaram teores inferiores ao limite de potabilidade, embora sejam sugestivos de poluição. Há indícios, portanto, de poluição das águas subterrâneas em $40 \%$ das amostras (Figura 8 b). Segundo Mendes e Oliveira (2004), os teores do nitrato maiores do que
$5 \mathrm{mg} . \mathrm{L}^{-1}$ podem indicar a poluição das águas naturais por despejos in natura de efluentes líquidos domésticos na massa da água. Os altos teores do nitrato na água subterrânea configuram falhas no saneamento básico e ambiental, sendo facilmente lixiviado da solução do solo ou no perfil do aquífero e persistente em condições aeróbicas (VARNIER et al., 2010).

Tabela 3 - Sumário estatístico das variáveis hidroquímicas nas amostras de água subterrânea (2010-2012). a) Amostras de 2010 (Chuvoso)

\begin{tabular}{|c|c|c|c|c|c|c|c|c|c|c|c|c|c|c|c|}
\hline \multirow{2}{*}{ Parâmetro } & ${ }^{\circ} \mathrm{C}$ & $\mathbf{m V}$ & & & \multicolumn{11}{|c|}{ mg.. $\mathrm{L}^{-1}$} \\
\hline & Temp. & ORP & pH & STD & $\mathrm{Na}^{+}$ & $\mathbf{K}^{+}$ & $\mathrm{Ca}^{2+}$ & $\mathrm{Mg}^{2+}$ & $\mathrm{Cl}^{-}$ & $\mathrm{HCO}_{3}^{-}$ & $\mathrm{SO}_{4}^{-}$ & $\mathrm{N}-\mathrm{NO}_{2}^{-}$ & $\mathrm{N}-\mathrm{NO}_{3}{ }^{-}$ & $\mathbf{F}^{-}$ & DT \\
\hline Mínimo & 26,30 & $-47,0$ & 6,60 & 253,70 & 3,28 & 0,79 & 27,86 & 5,81 & 10,40 & 145,66 & 2,02 & 0,02 & 0,35 & 0,11 & 102,65 \\
\hline Máximo & 31,20 & 93,0 & 8,10 & 638,30 & 111,04 & 4,06 & 194,45 & 43,75 & 656,00 & 378,85 & 92,50 & 2,10 & 17,00 & 2,15 & 666,38 \\
\hline Média & 28,16 & 53,7 & 7,18 & 418,99 & 26,45 & 2,11 & 118,52 & 17,33 & 140,57 & 246,74 & 37,10 & 0,67 & 6,26 & 0,58 & 351,90 \\
\hline Mediana & 27,80 & 59,3 & 7,05 & 387,08 & 16,62 & 2,14 & 117,38 & 16,01 & 109,80 & 237,73 & 33,30 & 0,54 & 4,15 & 0,38 & 355,41 \\
\hline Desvio Padrão & 1,26 & 32,8 & 0,41 & 118,09 & 25,88 & 0,19 & 9,27 & 2,00 & 32,98 & 12,34 & 5,20 & 0,62 & 1,08 & 0,10 & 141,67 \\
\hline Erro Padrão & 0,25 & 6,4 & 0,08 & 23,16 & 5,10 & 0,93 & 45,43 & 9,78 & 161,55 & 60,47 & 25,48 & 0,12 & 5,31 & 0,51 & 27,78 \\
\hline Valor de $p^{*}$ & $0,01 * *$ & $0,01^{* *}$ & $0,01 * *$ & $0,01 * *$ & $0,01 * *$ & $0,01 * *$ & $0,01 * *$ & $0,01 * *$ & $0,01 * *$ & $0,01 * *$ & $0,01^{* *}$ & $0,009 * *$ & $0,01 * *$ & $0,01 * *$ & $0,01 * *$ \\
\hline V.M.P.** & - & - & $6.5-9.5$ & 1000,00 & 200,00 & - & 75,00 & 50,00 & 250,00 & - & 250,00 & 1,00 & 10,00 & 0,80 & 500,00 \\
\hline
\end{tabular}

*Valor máximo permitido pela Portaria 2914/11, ou W.H.O (2006); *: distribuição gaussiana; ***: não gaussiana.

b) Amostras de 2011 (Chuvoso)

\begin{tabular}{|c|c|c|c|c|c|c|c|c|c|c|c|c|c|c|c|}
\hline \multirow{2}{*}{ Parâmetro } & \multicolumn{4}{|c|}{$\begin{array}{ll}{ }^{\circ} \mathbf{C} & \mathbf{m V} \\
\end{array}$} & \multicolumn{11}{|c|}{ mg.L ${ }^{-1}$} \\
\hline & Temp. & ORP & pH & STD & $\mathrm{Na}^{+}$ & $\mathbf{K}^{+}$ & $\mathrm{Ca}^{2+}$ & $\mathbf{M g}^{2+}$ & $\mathrm{Cl}^{-}$ & $\mathrm{HCO}_{3}^{-}$ & $\mathrm{SO}_{4}^{-}$ & ${\mathrm{N}-\mathrm{NO}_{2}^{-}}^{-}$ & $\mathrm{N}^{-\mathrm{NO}_{3}}{ }^{-}$ & $\mathbf{F}$ & DT \\
\hline Mínimo & 26,48 & $-20,00$ & 7,04 & 297,70 & 2,37 & 0,65 & 24,32 & 4,01 & 28,15 & 139,31 & 10,23 & 0,03 & 0,16 & 0,12 & 93,92 \\
\hline Máximo & 30,09 & 362,00 & 8,69 & 1170,0 & 83,25 & 4,86 & 220,50 & 40,73 & 460,00 & 364,59 & 98,86 & 0,42 & 15,13 & 1,79 & 682,36 \\
\hline Média & 28,36 & 169,74 & 7,71 & 573,01 & 21,86 & 1,93 & 117,29 & 16,29 & 121,16 & 264,41 & 38,76 & 0,11 & 5,46 & 0,60 & 348,98 \\
\hline Mediana & 28,43 & 188,50 & 7,75 & 533,50 & 14,59 & 1,93 & 119,70 & 14,75 & 91,10 & 268,60 & 34,08 & 0,07 & 3,33 & 0,39 & 356,23 \\
\hline Desvio Padrão & 0,84 & 92,01 & 0,37 & 212,14 & 20,71 & 0,93 & 52,09 & 8,88 & 106,63 & 62,69 & 21,07 & 0,11 & 4,76 & 0,48 & 149,65 \\
\hline Erro Padrão & 0,16 & 18,04 & 0,07 & 41,60 & 4,06 & 0,18 & 10,22 & 1,74 & 20,91 & 12,30 & 4,13 & 0,02 & 0,93 & 0,09 & 29,35 \\
\hline Valor de $p^{*}$ & $0,01 * *$ & $0,009^{* *}$ & $0,01 * *$ & $0,009 * *$ & $0,008^{* *}$ & $0,01 * *$ & $0,01 * *$ & $0,009^{* *}$ & $0,01 * *$ & $0,01^{* *}$ & $0,01 * *$ & $0,007^{* *}$ & $0,009^{* *}$ & $0,01 * *$ & $0,01 * *$ \\
\hline V.M.P.** & - & - & $6.5-9.5$ & 1000,00 & 200,00 & - & 75,00 & 50,00 & 250,00 & - & 250,00 & 1,00 & 10,00 & 0,80 & 500,00 \\
\hline
\end{tabular}

*Valor máximo permitido pela Portaria 2914/11, ou W.H.O (2006); *: distribuição gaussiana; ***: não gaussiana

c) Amostras de 2012 (Estiagem)

\begin{tabular}{|c|c|c|c|c|c|c|c|c|c|c|c|c|c|c|c|}
\hline \multirow{2}{*}{ Parâmetro } & \multirow{2}{*}{\multicolumn{2}{|c|}{$\begin{array}{cc}{ }^{\circ} \mathbf{C} & \mathbf{m V} \\
\text { Temp. } & \text { ORP } \\
\end{array}$}} & \multirow[b]{2}{*}{ pH } & \multirow[b]{2}{*}{ STD } & \multirow[b]{2}{*}{$\mathrm{Na}^{+}$} & \multirow[b]{2}{*}{$\mathbf{K}^{+}$} & \multirow[b]{2}{*}{$\mathrm{Ca}^{2+}$} & \multirow[b]{2}{*}{$\mathbf{M g}^{2+}$} & \multicolumn{3}{|c|}{ mg.. ${ }^{-1}$} & \multirow[b]{2}{*}{$\mathrm{N}^{-\mathrm{NO}_{2}}{ }^{-}$} & \multirow[b]{2}{*}{$\mathrm{N}^{-\mathrm{NO}_{3}}{ }^{-}$} & \multirow[b]{2}{*}{$\mathbf{F}$} & \multirow[b]{2}{*}{ DT } \\
\hline & & & & & & & & & $\mathrm{Cl}^{-}$ & $\mathrm{HCO}_{3}^{-}$ & $\mathrm{SO}_{4}^{-}$ & & & & \\
\hline Mínimo & 26,18 & $-38,00$ & 6,87 & 307,00 & 2,13 & 0,49 & 8,30 & 4,56 & 24,10 & 110,50 & 10,13 & 0,01 & 0,10 & 0,18 & 123,50 \\
\hline Máximo & 29,63 & 187,00 & 8,66 & 1230,0 & 67,81 & 5,26 & 96,30 & 34,82 & 578,50 & 297,00 & 85,16 & 0,11 & 16,40 & 2,13 & 634,21 \\
\hline Média & 27,96 & 94,65 & 7,78 & 578,00 & 22,46 & 1,74 & 112,64 & 16,06 & 124,01 & 209,19 & 38,76 & 0,05 & 5,07 & 0,61 & 355,86 \\
\hline Mediana & 27,91 & 115,50 & 7,57 & 525,50 & 15,59 & 1,58 & 120,80 & 15,42 & 91,80 & 205,60 & 37,50 & 0,05 & 2,37 & 0,37 & 372,09 \\
\hline Desvio Padrão & 0,96 & 66,67 & 0,49 & 132,78 & 19,36 & 1,02 & 45,87 & 7,46 & 117,69 & 48,92 & 19,99 & 0,02 & 5,41 & 0,54 & 123,46 \\
\hline Erro Padrão & 0,19 & 13,08 & 0,10 & 26,04 & 3,80 & 0,20 & 9,00 & 1,46 & 23,08 & 9,59 & 3,92 & 0,005 & 1,06 & 0,11 & 24,69 \\
\hline Valor de $p^{*}$ & $0,001 * *$ & $0,01 * *$ & $0,01 * *$ & $0,001^{* *}$ & $0,009 * *$ & $0,009 * *$ & $0,01 * *$ & $0,01^{* *}$ & 0,007 & $0,01 * *$ & $0,01 * *$ & $0,01^{* *}$ & $0,01 * *$ & $0,01 * *$ & $0,24 *$ \\
\hline V.M.P.** & - & - & $6.5-9.5$ & 1000,00 & 200,00 & - & 75,00 & 50,00 & 250,00 & - & 250,00 & 1,00 & 10,00 & 0,80 & 500,00 \\
\hline
\end{tabular}

*Valor máximo permitido pela Portaria 2914/11, ou W.H.O (2006); *: distribuição gaussiana; ***: não gaussiana. 
A análise espacial da distribuição dos teores do nitrato revelou que as restrições locais de potabilidade se situam no entorno da localidade da Agrovila 9, sede municipal, e das Agrovilas com dinâmicas urbanas destacadas (Figura 9a-b), que corrobora com a relevância do despejo de efluentes domésticos in natura como principal fonte de nitrato e para a poluição do aquífero cárstico-fissural. Verifica-se, também, um enriquecimento das amostras em cloreto ao longo do deslocamento do fluxo das águas subterrâneas e a influência do clima nas mudanças sazonais dos tipos hidroquímicos, de modo que a recarga com águas meteóricas adiciona íons bicarbonatos à solução no período chuvoso.
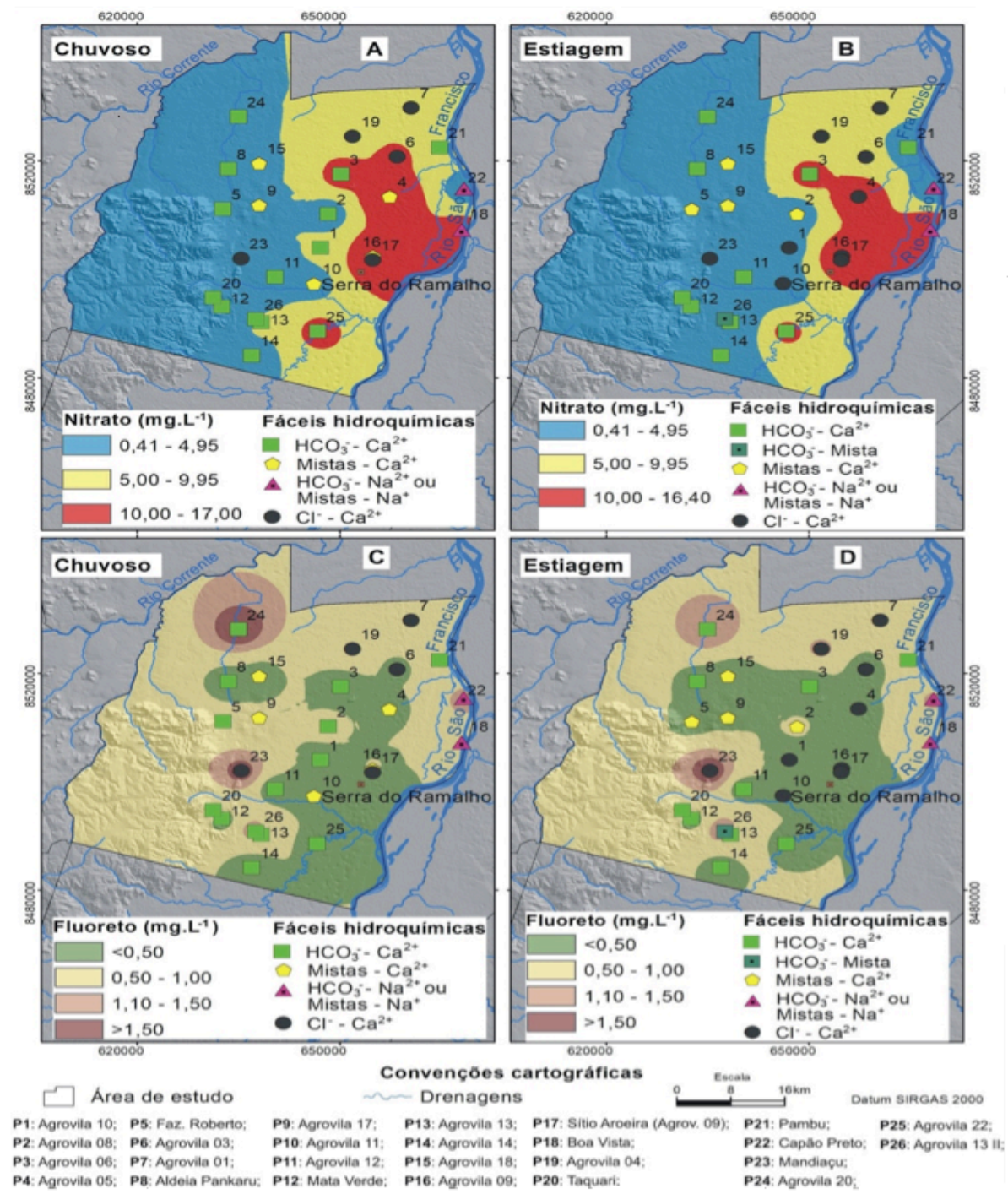

Figura 9

Distribuição espacial dos teores do nitrato $(A$ e $B)$ e do fluoreto $(C$ e $D)$ na área de estudo.

A distribuição de altos teores do nitrato nas águas subterrâneas de Serra do Ramalho demanda uma ampliação do acesso da população ao serviço público de cobertura do esgotamento sanitário adequado e de intervenções na melhoria do saneamento ambiental e para a promoção da saúde pública. Isto porque a ingestão de águas naturais com níveis tóxicos do nitrato pode causar agravos à saúde humana, a exemplo da metahemoglobinemia, ou síndrome do bebê azul, em especial nas crianças com até 6 meses de idade (KAPOOR; VIRARAGHAVAN, 1997).
De acordo com Silva e Araújo (2003) o nitrato se reduz a nitrito no intestino de adultos, formando as nitrosamidas ou nitrosaminas, as quais são substâncias carcinogênicas. Spiro e Stigliani (2009) destacaram que a relação entre a prevalência da metahemoglobinemia e a intoxicação por nitrato é um desafio à saúde pública nos países emergentes.

Em relação aos níveis do fluoreto, foram encontrados nas amostras valores que variaram entre 0,11 a $2,15 \mathrm{mg} . \mathrm{L}^{-1}$, com distribuição gaussiana (Tabela 3 ), cujas medianas não 
revelaram diferença estatística significativa sazonal entre as amostras, de acordo com o teste de Kruskal-Wallis $(p=0,98)$. Obteve-se $12 \%$ das amostras em desacordo com a Portaria $\mathrm{n}^{\mathrm{o}}$ 2914/11 (Brasil, 2012), e da Organização Mundial da Saúde (OMS) (WHO, 2006), as quais preconizam o limite de 1,5 $\mathrm{mg} . \mathrm{L}^{-1}$ para água potável.

A análise espacial revela uma distribuição norte-sul dos níveis tóxicos de fluoreto (Figura $9 \mathrm{c}-\mathrm{d}$ ), que talvez reflita a presença de controle geológico-estrutural e de mineralizações de fluorita roxa, especialmente nas localidades de Mandiaçu, Mata Verde e Agrovila 13 II, situadas de forma mais periférica e próximas da unidade geomorfológica da Serra do Ramalho, um alto topográfico regional. Ressalta-se que tais poços foram perfurados pela Companhia de Engenharia Hídrica e de Saneamento da Bahia - CERB, considerando a análise de fraturas e lineamentos como critério para a perfuração.

$\mathrm{Na}$ pesquisa de campo foram registrados corpos mineralizados e catas de fluorita roxa associadas as litofácies da Formação Sete Lagoas nas localidades de Mata Verde (P12), Taquari (P20) e Mandiaçu (P23). Miranda (1976), Misi et al. (2000) e Conceição Filho et al. (2003) descreveram a ocorrência e extração descontínua da fluorita roxa, desde 1960, ligada às litofácies calcilutitos e calcarenitos finos e cinza escuro da Fm. Sete Lagoas, nas localidades de Campo Alegre, Serra Solta, Serra de Campo Alegre, Morro dos Porcos, Santo Antônio, Água Branca e Lajedo, no Oeste da Bahia.

Em maior detalhe, observou-se que 23\% das amostras excederam o limite ótimo local de $0,8 \mathrm{mg} . \mathrm{L}^{-1}$ do fluoreto na água de consumo, que é uma medida de promoção da saúde bucal (Figura 10a). O teor ótimo de fluoreto $(\mathrm{C})$ foi calculado de acordo com Galagan e Vermillion (1957) (Equações 2-3), em função da temperatura média do ar $(\mathrm{T})$. Gallará et al. (2011) descreveram que o consumo de água com nível ótimo de fluoreto contribui para a proteção contra cárie ou contra fluorose dentária.

$$
\begin{aligned}
& €(T)=10,3+0,725 T \\
& C=22,2 / €
\end{aligned}
$$
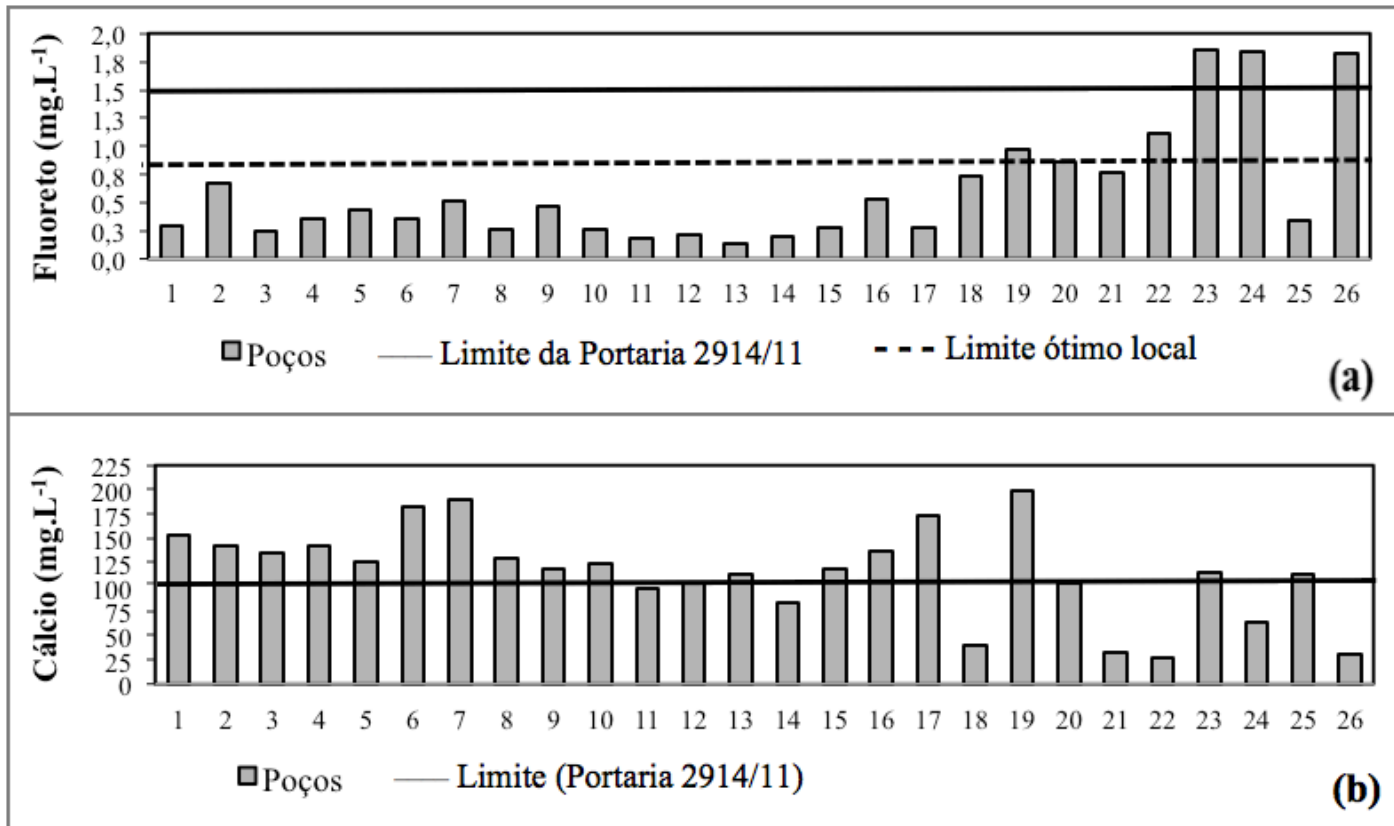

Diagrama de dispersão dos teores do fluoreto e do cálcio. A. Fluoreto $\left(F^{-}\right)$. B. Cálcio $\left(\mathrm{Ca}^{2+}\right)$.

Neste contexto, o consumo de água com níveis tóxico de fluoreto do Aquífero Bambuí representa um fator de risco de fluorose dentária, devendo ser monitorados pelos gestores dos serviços de saneamento e de vigilância em saúde ambiental no município de Serra do Ramalho, Oeste da Bahia. Segundo Cangussu et al. (2002), as proporções de fluorose dentária moderada e severa são menores nas áreas não endêmicas, ainda que 
apresentem alta prevalência de fluorose, em relação as áreas endêmicas, cuja maior severidade decorre do consumo de águas com níveis elevados naturais de flúor. Este cenário foi desvelado em decorrência das investigações científicas realizadas, dentre outras, no México (VAZQUEZ-ALVARADO et al., 2010; Jarquín-Yañez et al., 2015), na China (DING et al., 2011), na Argentina (AZCURRA et al., 1995; GALLARÁ et al., 2011; GARCÍA et al., 2012) e Cuba (LARQUIN et al., 2015).

Velásquez et al. (2006), Ferreira et al. (2010), Costa et al. (2013) e Cruz et al (2015) encontraram prevalências e severidade de fluorose dentária no Norte de Minas Gerais e no Oeste da Bahia associada a ingestão da água com níveis tóxicos no Aquífero Bambuí. A prevalência da fluorose dentária no Norte de Minas Gerais variou entre 57 a 67\%, com 35\% dos casos distribuídos nas categorias de moderado a severo. No município de Santana, no Oeste da Bahia, a prevalência da fluorose dentária foi de $53 \%$, com $18 \%$ dos casos nas categorias de moderado a severo. Esse perfil da fluorose dentária se mostrou em desacordo com os dados do levantamento nacional de saúde bucal, o Projeto SB Brasil 2010, o qual obteve uma prevalência de fluorose dentária nacional de $17 \%$, sendo registrada uma proporção de 1,5\% distribuída nas formas moderada ou severa (Brasil, 2010).

Propõe-se que a dissolução dos minerais calcita e dolomita das rochas do Grupo Bambuí, pelo $\mathrm{CO}_{2}$, fornece íons $\mathrm{Ca}^{2+}$ e $\mathrm{Mg}^{2+}$ para as águas subterrâneas de Serra do Ramalho (Equações 4 e 6). $\mathrm{Na}$ solução, as atividades dos íons $\mathrm{Ca}^{2+}, \mathrm{F}^{-}$e $\mathrm{HCO}_{3}{ }^{-}-\mathrm{CO}_{3}{ }^{2-}$ são interdependentes (HANDA, 1975; RAO, 2011). De acordo com Apambire et al. (1997), a saturação da solução na fase mineral calcita controla a solubilidade da fluorita, por conta do efeito de íon comum e abundância da calcita na água. Entretanto, nas condições alcalinas predomina a reação inversa, que precipita a calcita (HYPÓLITO et al., 2011). Desta forma, pode ocorrer dissolução da fluorita nas amostras saturadas em calcita e dolomita, naquelas águas mais alcalinas e sob altas temperaturas do ar, e a coprecipitação dos íons $\mathrm{Ca}^{2+}{\mathrm{e} \mathrm{HCO}_{3}}^{-}$.

$$
\begin{aligned}
& \mathrm{CaF}_{2} \leftrightarrow \mathrm{Ca}^{2+}+2 \mathrm{~F}^{-} \\
& \mathrm{CaCO}_{3}+\mathrm{CO}_{2}+\mathrm{H}_{2} \mathrm{O} \leftrightarrow \mathrm{Ca}^{2+}+2 \mathrm{HCO}_{3}^{-} \\
& \mathrm{CaMg}\left(\mathrm{CO}_{3}\right)_{2}+2 \mathrm{CO}_{2}+2 \mathrm{H}_{2} \mathrm{O} \leftrightarrow \mathrm{Ca}^{2+}+\mathrm{Mg}^{2+}+4 \mathrm{HCO}_{3}^{-}
\end{aligned}
$$

(Equação 4)

(Equação 5)

(Equação 6)
Verifica-se, em alguma medida, haver uma relação inversa entre os teores do fluoreto e cálcio, isto porque a saturação da solução em calcita controla a dissolução do mineral fluorita (Figura 10b). Handa (1975) propôs um modelo hidrogeoquímico do flúor que elucida a correlação entre $\mathrm{F}^{-}, \mathrm{Ca}^{2+}$ e $\mathrm{HCO}_{3}^{-}$, em condições de $\mathrm{pH}$ relativamente constante, como sintetizado na Equação 7, de modo $\mathbf{K}$ e a são respectivamente a constante de solubilidade e a atividade iônica. Gonçalves et al. (2018) propuseram que o modelo conceitual elaborado por Handa (1975), e modificado por Rao (2011), pode ser aplicado, após efetuada uma adaptação, ao estudo hidrogeoquímica do flúor no Aquífero Bambuí.

$$
\mathrm{KCaF}_{2} \leftrightarrow \mathrm{CaCO}_{3}=\left[\alpha\left(\mathrm{HCO}_{3}^{-}\right)\right] /\left[\alpha\left(\mathrm{H}^{+}\right) .\left(\mathrm{F}^{-}\right)^{2}\right]
$$

A Tabela 4 apresenta um sumário estatístico dos cátions multivalentes e mostra que os níveis dos elementos-traço $\mathrm{Pb}^{2+}, \mathrm{Cd}^{2+}$ ( $2^{\mathrm{a}}$ campanha), $\mathrm{Cu}^{2+}$ e $\mathrm{Zn}^{4+}$ (90\% das amostras) foram inferiores ao limite de quantificação do método analítico nas amostras. Os teores dos elementos menores e metais-traços na fração total contribuem para a composição hidroquímica e qualidade das águas subterrâneas. Para tanto, destacam-se o intemperismo químico das fases calcita, dolomita, fluorita $\left(\mathrm{CaF}_{2}\right)$, barita $\left(\mathrm{BaSO}_{4}\right)$, esfarelita $(\mathrm{Fe}, \mathrm{ZnS})$, galena $(\mathrm{PbS})$, pirita $\left(\mathrm{FeS}_{2}\right)$, calcopirita $\left(\mathrm{Cu}, \mathrm{FeS}_{2}\right)$, siderita $\left(\mathrm{FeCO}_{3}\right)$, celestita $\left(\mathrm{SrSO}_{4}\right)$, estrocionita $\left(\mathrm{SrCO}_{3}\right)$, entre outras. Estas fases minerais são encontradas, de acordo com Misi et al. (2007), disseminadas nas litofácies pelito-carbonáticas do Grupo Bambuí, na Bahia. 
Tabela 4 - Resultados das análises dos elementos principais, menores e metais-traços (total) nas amostras de água subterrânea coletadas em novembro de 2011 e julho de 2012.

\begin{tabular}{|c|c|c|c|c|c|c|c|c|c|c|c|c|c|}
\hline \multirow{2}{*}{ Estimador Amostral } & \multicolumn{13}{|c|}{ mg..$^{-1}$} \\
\hline & $\mathrm{Na}^{+}$ & $\mathbf{K}^{+}$ & $\mathrm{Ca}^{2+}$ & $\mathrm{Mg}^{2+}$ & $\mathrm{Fe}^{2+}$ & $\mathrm{Mn}^{2+}$ & $\mathrm{Sr}^{2+}$ & $\mathbf{A l}^{3+}$ & $\mathrm{Ba}^{2+}$ & $\mathrm{Zn}^{4+}$ & $\mathrm{Cu}^{2+}$ & $\mathrm{Cd}^{2+}$ & $\mathbf{P b}^{2+}$ \\
\hline Tamanho $(\mathrm{N})$ & 52 & 52 & 52 & 52 & 52 & 52 & 52 & 52 & 52 & 5 & 23 & 17 & 0 \\
\hline Mínimo & 2,13 & 0,49 & 24,32 & 4,01 & 0,01 & 0,01 & 0,05 & 0,03 & 0,007 & 0,02 & 0,02 & 0,002 & - \\
\hline Máximo & 83,25 & 5,26 & 220,50 & 40,73 & 0,22 & 0,39 & 4,96 & 0,69 & 0,19 & 0,20 & 0,06 & 0,01 & - \\
\hline Média & 22,46 & 1,83 & 114,91 & 16,16 & 0,04 & 0,03 & 0,79 & 0,26 & 0,07 & 0,06 & 0,01 & 0,003 & - \\
\hline Mediana & 15,26 & 1,76 & 120,41 & 15,21 & 0,03 & 0,01 & 0,44 & 0,27 & 0,06 & 0,03 & 0,07 & 0,002 & - \\
\hline Desvio Padrão & 20,37 & 0,97 & 48,76 & 8,13 & 0,04 & 0,07 & 0,98 & 0,10 & 0,04 & 0,07 & 0,01 & 0,003 & - \\
\hline Erro Padrão & 2,82 & 0,13 & 6,76 & 1,13 & 0,006 & 0,01 & 0,14 & 0,01 & 0,006 & 0,04 & 0,003 & 0,0006 & - \\
\hline Coeficiente de Variação (\%) & 90,69 & 52,82 & 42,44 & 50,34 & 112,37 & 276,84 & 124,58 & 37,60 & 56,23 & 130,7 & 132,64 & 77,76 & - \\
\hline Valor Máximo Permitido* & 200,00 & - & 75,00 & 50,00 & 0,30 & 0,20 & - & 0,70 & 0,10 & 5,0 & 2,00 & 0,005 & 0,01 \\
\hline LQM (CONAMA 396/08) & 0,01 & 0,005 & 0,01 & 0,01 & 0,002 & 0,007 & 0,001 & 0,003 & 0,003 & 0,02 & 0,002 & 0,002 & 0,01 \\
\hline
\end{tabular}

Observa-se que os teores totais dos elementos-traço ferro e alumínio nas amostras de água subterrânea do município de Serra do Ramalho variaram respectivamente entre 0,01 e 0,22 (mediana de $0,03 \mathrm{mg} . \mathrm{L}^{-1}$ ) e de 0,03 a $0,69 \mathrm{mg} . \mathrm{L}^{-1}$ (mediana de $0,27 \mathrm{mg} . \mathrm{L}^{-1}$ ), como foi mostrado na Tabela 4. Estes elementostraço são inseridos no padrão organoléptico de potabilidade, o qual não admite efeitos tóxicos comprovados, sendo, assim, indesejáveis por causarem inconvenientes às águas de distribuição (MENDES; OLIVEIRA, 2004). Esta observação é condizente com a Portaria $n^{\circ}$. 2.914/11 (BRASIL, 2012).

Nas condições alcalinas das amostras espera-se que o ferro ocorra na forma ferrosa $\left(\mathrm{Fe}^{2+}\right)$, complexado com carbonatos e hidroxila, podendo ser disponibilizado à solução pela oxidação das fases minerais pirita e calcopirita. O ferro é um metal pesado, sólido nas condições normais, anfótero, sendo encontrado, frequentemente, na forma de íon ferroso $\left(\mathrm{Fe}^{2+}\right)$ para os valores do $\mathrm{pH}$ de 4,5 a 9,0 .

Destacam-se as espécies hidratadas nas águas subterrâneas alcalinas de Serra do Ramalho, de modo que o alumínio total dissolvido na solução representa a soma dos teores das espécies individuais. Deve-se ser

\subsection{CARACTERIZAÇÃO ISOTÓPICA}

As medidas dos isótopos estáveis da molécula da água mostraram-se empobrecidas em relação aos padrões V-SMOW e V-PDB (Tabela 5), sendo atribuído à progressiva depleção dos valores dos isótopos pesados em decorrência da ação do efeito continental, de apontado, igualmente, que nas águas com excesso do fluoreto espera-se que o alumínio possa ser encontrado tanto nas formas químicas de íons bivalente $\left(\mathrm{AlF}^{2+}\right)$ ou de íons trivalente $\left(\mathrm{AlF}^{3+}\right)$. A maior parte da ingestão do alumínio é proveniente dos alimentos, através de diferentes formas, sendo o Al na água a forma mais biodisponível e absorvida pelo intestino (MATÍAS-CERVANTES et al., 2018). Segundo Walton (2007), o alumínio é um elemento-traço não essencial para a saúde humana, em que as supostas situações de toxidade se associam aos pacientes renais, podendo causar alterações ósseas e nervosas e talvez represente um fator de risco ambiental correlacionado ao mal Alzheimer.

Os níveis de bário $\left(\mathrm{Ba}^{2+}\right)$ obtidos nas amostras podem advir da fase mineral barita $\left(\mathrm{BaSO}_{4}\right)$ (Tabela 4). De acordo com Lima (2010), o bário é um metal alcalino terroso encontrado especialmente na barita, em que os compostos têm baixa toxidade devido a reduzida solubilidade dos sais de bário. $\mathrm{O}$ intemperismo químico de minerais das rochas libera o bário às águas naturais, de modo que as concentrações deste elemento na solução variam em função da solubilidade da barita (HEM, 1985).

Tabela 5 - Resultado estatístico dos parâmetros isótopos estáveis medidos sazonalmente na água subterrânea.

\begin{tabular}{|c|c|c|c|c|c|c|c|c|c|c|c|c|c|c|c|}
\hline \multirow{2}{*}{ Parâmetro } & \multicolumn{5}{|c|}{ Dezembro de 2010(Chuvoso) } & \multicolumn{5}{|c|}{ Novembrode 2011 (Chuvoso) } & \multicolumn{5}{|c|}{2012 (Estiagem) } \\
\hline & Mín. & Máx. & Média & Mediana & Valor dep* & Mín. & Máx. & Média & Mediana & Valordep* & Mín. & Máx. & Média & Mediana & Valor dep* \\
\hline$\delta \mathrm{D}(\%)$ & $-37,30$ & $-22,70$ & $-28,50$ & $-27,30$ & $0,09 * *$ & $-39,10$ & $-22,10$ & $-4,60$ & $-4,50$ & $0,33 * *$ & $-39,40$ & $-22,40$ & $-29,40$ & $-28,70$ & $0,34 * *$ \\
\hline$\delta^{18} \mathrm{O}(\%)$ & $-5,20$ & $-3,40$ & $-4,30$ & $-4,40$ & $0,84^{* *}$ & $-5,90$ & $-3,50$ & $-9,60$ & $-10,70$ & $0,55^{* *}$ & $-5,90$ & $-2,90$ & $-4,60$ & $-4,60$ & $0,69^{* *}$ \\
\hline $\mathrm{d}(\%)$ & $-2,40$ & 11,40 & 6,19 & 6,50 & $0,03^{* * *}$ & 0,10 & 12,20 & 6,84 & 7,30 & $0,64^{* *}$ & $-1,30$ & 11,30 & 7,17 & 7,40 & $0,049 * * *$ \\
\hline
\end{tabular}

D: Excesso de deutério; * teste de normalidade de Shapiro-Wilk; **Distribuição gaussiana; ***Distribuição não gaussiana. 
Os diagramas do tipo box plots apresentados na Figura 11 apontaram haver uma similaridade na distribuição da razão isotópica das amostras, reportando-se a mesma origem e semelhante condições de recarga. Considerando a distribuição gaussiana, como

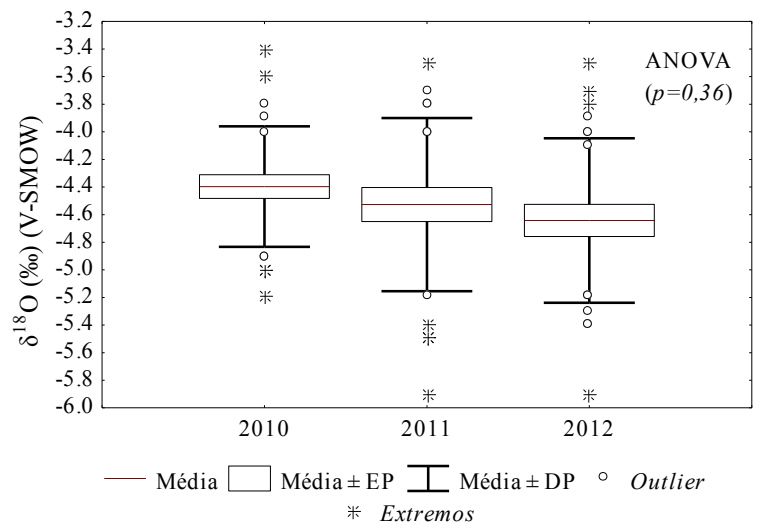

(a) mostrado na Tabela 5, foi aplicado o teste de comparações múltiplas $(A N O V A)$, revelando que as médias das variáveis isotópicas $\delta^{18} \mathrm{O}$ $(p=0,36)$ e $\delta^{2} \mathrm{H} \quad(p=0,72)$ não diferiram significativamente entre as campanhas amostrais (2010-2012).

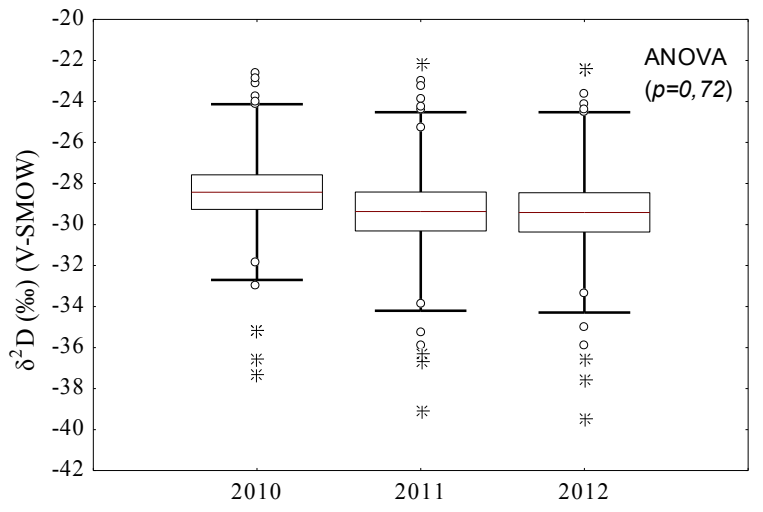

(b)

Figura 11

Diagramas de box plots aplicados na comparação sazonal dos parâmetros isotópicos $\left(\delta^{18} \mathrm{O}, \delta^{2} \mathrm{H}\right)$ - (a) e (b) representam respectivamente a variação sazonal dos isótopos de oxigenios e do deutério.

Os valores do d-excess, "excesso de deutério" (d) se distribuíram entre $-2,4$ e $12,2 \%$ (V-SMOW) nas amostras de água do Aquífero Bambuí, no município de Serra do Ramalho (Tabela 5), em que os valores da mediana não diferiram de forma significativa entre as campanhas amostrais, de acordo com o teste de Kruskal-Wallis $(p=0,29)$, aplicado para dados não gaussianos. Esta similaridade entre as amostras destaca a relevância do clima à composição isotópica e recarga do Aquífero Bambuí.
A Figura 12 mostra o diagrama $\delta^{2} \mathrm{H}-\delta^{18} \mathrm{O}$ das amostras de água subterrânea (2010-2012), sendo considerada representativa a seguinte equação da reta de ajuste linear: $\delta \mathrm{D}=6,9 \delta^{18} \mathrm{O}$ $+1,9\left(\mathrm{r}=0,87 ; \mathrm{R}^{2}=0,76\right)$. Esta reta apresentou o coeficiente angular levemente inferior a inclinação da Linha Meteórica Global (LMG). Portanto, infere-se que as amostras de água subterrânea tiveram origem nas águas meteóricas, que sofreram ligeira evaporação durante a infiltração rápida nas unidades aquíferas.

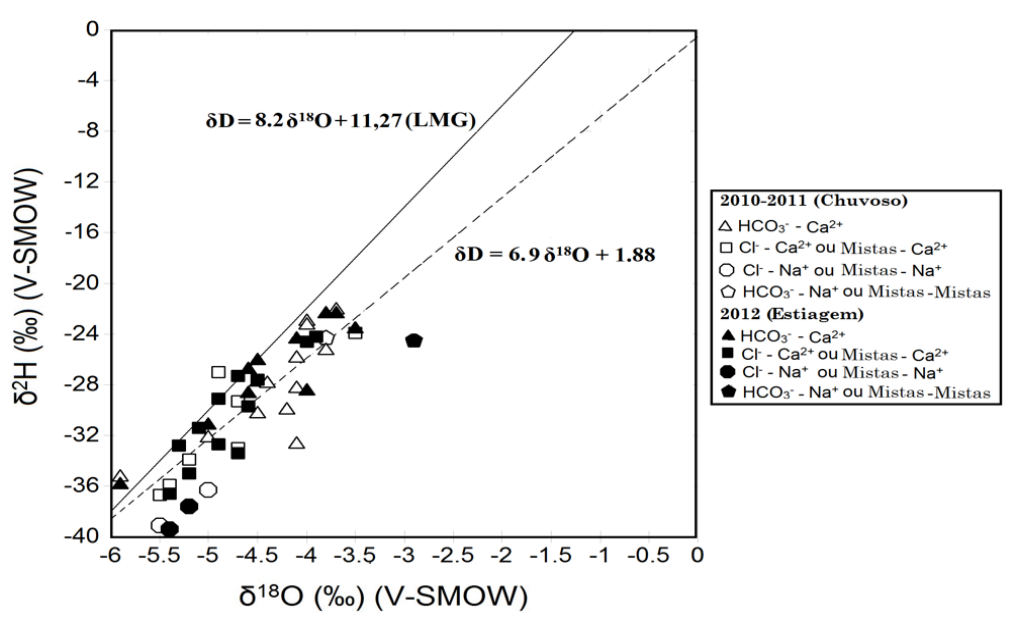

Diagrama da razão isotópica $\delta^{18} \mathrm{O}$ x $\delta \mathrm{D}$ das amostras de água subterrânea e indicação dos fácies hidroquímicos, no município de Serra do Ramalho, Bahia (linha meteórica global de Rozanski et al., 1993).

A Figura 12 mostra uma separação das amostras de acordo com as associações entre as fácies hidroquímicos e a assinatura isotópica. As fácies bicarbonatadas cálcicas abrangem dois subdomínios, um deles constituído das amostras mais enriquecido no isótopo pesado de $\delta \mathrm{D}(-26,10$ a $-21,20 \% \mathrm{~V}$ SMOW), que podem ter sofrido evaporação ao 
longo do fluxo da água subterrâneo. O subdomínio das águas menos enriquecidas $(-35,90$ a $-28,50 \%$ V-SMOW), que foram coletadas na Aldeia Pankaru (P08), Agrovila 14 (P14), Mata Verde (P24) e na Agrovila 13 II (P26), podem ter sofrido menor evaporação e rápida infiltração por meio de feições cárstica, situando-se próximo as zonas de recarga.

As fácies hidroquímicas cloretadas cálcicas revelaram valores em $\delta \mathrm{D}$ de $-36,65 \%$ a $-27,26$ $\%$ V-SMOW (Figura 12). Enquanto que as fácies mistas cálcicas contemplaram os valores de -33,36\% a -27,62\% V-SMOW. Verifica-se, igualmente, a presença das fácies bicarbonatadas sódicas, ou mistas sódicas, ou mistas-mistas nas localidades de Boa Vista (P18) e Capão Preto (P22), situadas próximo às margens do rio São Francisco, com valores da razão isotópica entre $-39,40 \%$ e $-37,59 \%$ (VSMOW). As fácies cloretadas cálcicas ocorrem na zona de descarga do sistema aquífero e na área de maior aridez do clima, a qual aumenta de oeste para leste na área de estudo, na direção rio São Francisco.

\section{CONCLUSÕES}

Nas amostras de água subterrânea de Serra do Ramalho, no contexto do Aquífero Bambuí, destacaram-se as fácies hidroquímicas bicarbonatadas cálcicas ou mistas cálcicas. A análise da razão isotópica da água $\left(\delta^{2} \mathrm{H}\right.$ e $\left.\delta^{18} \mathrm{O}\right)$ indicou a relevância da recarga pelas chuvas locais, havendo infiltração rápida e pouca evaporação. Esta tendência pode ser corroborada pela assinatura hidrogeoquímica.

A análise de agrupamento apontou que as diferenças na mineralização, razões geoquímicas e os valores dos índices de saturação das fases minerais modelizados explicariam a formação dos grupos hidroquímicos, e contribuíram para a compreensão dos efeitos da sazonalidade à hidrogeoquímica. Foi sugerido um modelo conceitual hidrogeoquímico, o qual indicou aumento da mineralização desde as áreas próximas as zonas de recarga do aquífero e a

\section{AGRADECIMENTOS}

Agradece-se ao Conselho Nacional de Desenvolvimento Científico e Tecnológico (CNPq) pelas bolsas de doutorado e pelo financiamento do
Observa-se, no geral, haver uma similaridade entre a inclinação das retas da razão isotópica do Aquífero Bambuí, nesta pesquisa e aquelas de Camurugy (2009), Gonçalves (2014), Carvalho (2018), Gonçalves et al. (2019b) ou dos dados de Lousada e Campos (2011) para as chuvas de Brasília (DF).

Lousada e Campos (2011) encontraram a reta dada pela equação $\delta \mathrm{D}=7,6 \delta^{18} \mathrm{O}+10,2$ da razão isotópica das chuvas de Brasília. Bedmar e Silva (1980) obtiveram a reta $\delta \mathrm{D}=6,21 \delta^{18} \mathrm{O}$ $+2,6 \quad\left(\mathrm{R}^{2}=0,55\right)$ das águas do Aquífero Bambuí, no Norte de Minas Gerais. No Aquífero Bambuí, na Bahia, Camurugy (2009) e Carvalho (2018) obtiveram, nesta ordem, as seguintes retas da razão isotópica: $\delta \mathrm{D}=7,41$ $\delta^{18} \mathrm{O}+8,92\left(\mathrm{R}^{2}=0,80\right)$ e $\delta \mathrm{D}=7,64 \delta^{18} \mathrm{O}+$ $18,4\left(\mathrm{R}^{2}=0,86\right)$. Gonçalves (2014) apresentou as retas de ajuste linear da razão isotópica das águas do Aquífero Bambuí, Bahia, coletadas nos períodos chuvoso (2010) e de estiagem (2012): $\delta \mathrm{D}=7,22 \delta^{18} \mathrm{O}+2,9\left(\mathrm{R}^{2}=0,79\right)$ e $\delta \mathrm{D}=$ $7,5 \delta^{18} \mathrm{O}+5,2\left(\mathrm{R}^{2}=0,71\right)$.

evolução das fácies hidroquímicas bicarbonatadas cálcicas para as fácies bicarbonatadas ou cloretadas sódicas, de acordo com a circulação da água no aquífero, interação água-rocha, do tempo de trânsito, atuação das reações de troca de bases e do clima.

A avaliação dos teores dos parâmetros químicos quanto aos padrões de potabilidade (Portaria 2914/11, WHO, 2006) resultou na identificação de inconformidades e assim sugere-se que os gestores dos recursos hídricos e da saúde deste município apliquem tecnologias de desfluoretação das águas com níveis tóxicos de flúor usadas no abastecimento e monitorem os teores do nitrato, fluoreto e metais-traço, desde que sejam consideradas as suas múltiplas relações entre saúde e o meio ambiente.

Projeto de Pesquisa Hidrogeoquímica dos Aquiferos Cársticos de Irecê e Serra do Ramalho, Bahia, no Edital Universal do CNPq no 14/2011. 


\section{REFERÊNCIAS}

APHA. - AMERICAN PUBLIC HEALTH ASSOCIATION. 1995. Standard Methods for Examination of Water and Wastewater. 19 th ed. Washington: American Water Works Association.

APAMBIRE, W.B., BOYLE, D.R., MICHEL, F. A. 1997. Geochemistry, genesis, and health implications of fluoriferous groundwaters in the upper Regions of Ghana. Environmental Geology, 33: 13-24.

ARMENGAUD, A., KOSTER, R.D., JOUZEL, J., CIAIS, P. 1998. Deuterium excess in Greenland snow: Analysis with simple and complex models. Journal of Geophysical Research: Atmospheres, 103: 8947-8953.

AZCURRA, A.I., BATTELLINO, L.J., CALAMARI, S.E., DORRONSORO DE CATTONI, S.T., KREMER, M.; LAMBERGHINI, F.C. 1995. Estado de salud bucodental de escolares residentes en localidades abastecidas con agua de consumo humano de muy alto y muy muy bajo contenido de fluoruros. Rev. Saúde Pública, 29: 364-375.

BAIRD, C.; CANN, M. 2011. Química ambiental. 4. ed. Porto Alegre: Bookman.

BEDMAR, A.P.; SILVA, A. B. 1980. Utilização de isótopos ambientais na pesquisa de recursos hídricos subterrâneos no karste da região do Jaíba, norte de Minas Gerais. Revista Brasileira de Geociências, 10: 276-29.

BIGUELINI, C. P., GUMY, M. P., GUMY. 2012. Saúde ambiental: índices de nitrato em águas subterrâneas de poços profundos na região Sudoeste do Paraná. Revista Faz Ciência, 14: 20, 153, 2012.

BRAND, W.A., AVAK, H., SEEDORF, R., HOFMANN, D., CONRADI, T. 2000. New methods for fully automated isotope ratio determination from hydrogen at the natural abundance level. Geoph. Prosp, 28: 967-976.

BRASIL. Conselho Nacional do Meio AmbienteCONAMA. 2008. Resolução $n^{\circ}$. 396, de 3 de abril de 2008. Dispõe sobre a classificação $e$ diretrizes ambientais para o enquadramento das águas subterrâneas e dá outras providências. Diário Ofícial da União.

BRASIL. Ministério da Saúde. 2010. Secretaria de Atenção à Saúde. Departamento de Atenção Básica. Coordenação Nacional de Saúde Bucal. Projeto SB Brasil 2010 - Condições de saúde bucal da população brasileira 2010: resultados principais. Brasília: MS-CNSB.

BRASIL. Ministério da Saúde. 2012. Portaria 2914 de 12 de dezembro de 2011. Dispõe sobre os procedimentos de controle e de vigilância da qualidade da água para consumo humano e seu padrão de potabilidade. Diário Oficial da União.

CAMURUGY, E. B. 2009. Uso da hidroquímica e isótopos estáveis $(\delta \mathrm{D}$ e $\delta 18 \mathrm{O})$ no estudo da qualidade e origem das águas subterrâneas do aquífero cárstico da região oeste do Estado da Bahia. Monografia de Graduação. Universidade Federal da Bahia. Instituto de Geociências, Salvador, $66 \mathrm{p}$.

CANGUSSU, M.C.T., NARVAI, P.C., FERNANDEZ, R.C., DJEHIZIAN, V. 2002. A fluorose no Brasil: uma revisão crítica. Cad Saúde Pública, 1: 7-15.

CARVALHO, J. V. 2018. Hidrogeoquímica e Isótopos estáveis das águas subterrâneas do Aquífero Bambuí (Bahia, Brasil). Dissertação de Mestrado, Universidade Federal da Bahia. Instituto de Geociências, Salvador, Brasil, 53p.

CLARK, I.; FRITZ, P. 1997. Environmental Isotopes in Hydrology. $2^{\mathrm{a}}$ ed. New York, Lewis Publishers, 328p.

CONCEIÇÃO FILHO, V. M., MONTEIRO, D. M., RANGEL, P. D. A., GARRIDO, I. D. A. 2003. Bacia do São Francisco entre Santa Maria da Vitória e Iuiú, Bahia: geologia e potencialidade econômica. Salvador, CBPM, 76p.

COSTA, D.A. 2011. Controle lito-estrutural e estratigráfico na hidrogeoquímica e nas concentrações de fluoreto no Sistema Aquífero Cárstico - Fissural do Grupo Bambuí, norte de Minas Gerais. Dissertação de Mestrado. Universidade Federal de Minas Gerais. Instituto de Geociências, Belo Horizonte, 131 p.

COSTA, S. DE M., ABREU, M.H.N.G., VARGAS, A.M.D., VASCONCELOS, M., FERREIRA, E., CASTILHO, L.S. DE. 2013. Cárie dentária e fluorose endêmica em distritos rurais de Minas Gerais, Brasil. Rev Bras Epidemiol, 16: 10211028.

CRAIG, H. 1957. Isotopic standards for carbon and oxygen and correction factors for mass spectrometric analysis of carbon dioxide. Geochemica Cosmochimica Acta, 12: 181-186.

CRUZ, M.J.M., COUTINHO, C.A.M., GONÇALVES, M.V.P. 2015. The Dental fluorosis on Santana karst region, Bahia State, Brazil. Journal of Geography, 3: 51-67.

DANSGAARD, W.1964. Stable isotopic in precipitation. Tellus, 16: 436-467.

DING, Y., SUN, H., HAN, H., WANG, W., JI, X., LIU, X., SUN, D. 2011. The relationships between low levels of urine fluoride on children's intelligence, dental fluorosis in endemic fluorosis areas in Hulunbuir, Inner Mongolia, China. Journal of hazardous materials, 186: 1942-1946.

EPSTEIN, S.; MAYEDA, T. 1953. Variations of ${ }^{18} \mathrm{O}$ content of waters from natural sources. Geochimica et Cosmochimica Acta, 4: 213-221.

FERREIRA, E.F., VARGAS, A.M.D., CASTILHO, L.S., VELÁSQUEZ, L.N.M.; FANTINEL, L.M., ABREU, M.H.N.G. 2010. Factors Associated to Endemic Dental Fluorosis in Brazilian Rural Communities. Int J Environ Res Public Health, 7: 3115-3128. 
GALAGAN, D. J.; VERMILLION, J. R. 1957. Determining optimum fluoride concentrations. Public health reports, 72: 491.

GASSER, R. S.; CRUZ, M. J. M.; GONÇALVES, M. V. P. Avaliação da vulnerabilidade intrínseca a contaminação do aquífero cárstico Salitre no município de Cafarnaum, Bahia. Águas Subterrâneas, 32: 1, p.70-78, 2018.

GALlARÁ, R. V., PIAZZA, L. A., PIÑAS, M. E., BARTEIK, M. E., MONCUNILL, I.,; PONCE, R. H. 2011. Fluorosis endémica en zonas rurales del norte y noreste de la provincia de Cordoba, Argentina. Revista de Salud Pública, 15: 40-48.

GARCÍA, M., LECOMTE, K.L., STUPAR, Y., FORMICA, S.M., BARRIONUEVO, M., VESCO, M., GALLARÁ, R., PONCE, R. 2012. Geochemistry and health aspects of F-rich mountainous streams and groundwaters from sierras Pampeanas de Cordoba, Argentina. Environmental Earth Sciences, 65: 535-545.

GAT, J.R. 1971. Comments on the stable isotope method in regional groundwater investigations. Water Resources Research. 7: 980-993.

GIBBS, R. J. 1970. Mechanisms controlling world water chemistry. Science, 170: 1088-1090.

GHESQUIÈRE, O., WALTER, J., CHESNAUX, R., ROULEAU, A. 2015. Scenarios of groundwater chemical evolution in a region of the Canadian Shield based on multivariate statistical analysis. Journal of Hydrology: Regional Studies, 4: 246-266.

GONÇALVES, M.V.P. 2014. Flúor no Aquífero Bambuí no Sudoeste da Bahia (Brasil). Tese de Doutorado. Universidade Federal de Minas Gerais. Instituto de Geociências, Belo Horizonte, $193 \mathrm{p}$.

GONÇALVES, M. V. P., Cruz, M. J. M., Santos, R. A., Junior, A. B. D. S. R., Coutinho, C. A. M. 2018. Flúor na Água do Aquífero Bambuí no Oeste da Bahia (Brasil). Brazilian Journal of Aquatic Science and Technology, 22: 1, 10-21.

GONÇALVES, M. V. P., SANTOS, R. A., JUNIOR, A. B. D. S. R., COUTINHO, C. A. M., CRUZ, M. J. M., DA CUNHA, M. P. 2019a. Flúor nas águas subterrâneas dos municípios de Feira da Mata e Santana (BA): comparação dos teores do fluoreto e seu significado na saúde da população. Geochimica Brasiliensis, 33: 2, 175-187.

Gonçalves, M. V. P., Santos, R. A., Junior, A. B. D. S. R., BATISTA, F. S., CRUZ, M. J. M., DA CUNHA, M. P., COSTA, A. B. $2019 \mathrm{~b}$. Composição isotópica $\left(\delta^{18} \mathrm{O}, \delta^{2} \mathrm{H}\right.$ e $\left.\delta^{13} \mathrm{C}_{\mathrm{CID}}\right)$ das águas subterrâneas dos municípios de Feira da Mata e Santana (BA). Geochimica Brasiliensis, 33: 3, 313-324.

GONÇALVES, M. V. P., SANTOS, R. A., COUTINHO, C. A. M., CRUZ, M. J. M. 2020. Fluoride Levels in the Groundwater and Prevalence of Dental Fluorosis in the Municipality of Santana, in Region Karstic of West Bahia, Brazil. In Groundwater Hydrology. IntechOpen.
HANDA, B. K. 1975. Geochemistry and genesis of Fluoride-Containing ground waters in india. Groundwater, 13: 275-281.

HEM, J. D. 1985. Study and interpretation of the chemical characteristics of natural water (Vol. 2254). Department of the Interior, US Geological Survey.

HYPOLITO, R, EZAKI, S., ANDRADE, S. 2011. Geoquímica da Interação Água/Rocha/Solo: Estudos Preliminares. $1^{\text {a }}$ ed. São Paulo: ALL PRINT, 454 pp.

KAPOOR, A.; VIRARAGHAVAN, T. Nitrate removal from drinking water. 1997. Journal of Environmental Engineering, 123, 4, p.371-380.

KOHFAHL, C., SPRENGER, C., HERRERA, J.B., MEYER, H., CHACÓN, F.F., PEKDEGERA, A. 2008. Recharge Sources and Hydrogeochemical Evolution of Groundwater in Semiarid and Karstic Environments: A Field Study in the Granada Basin (Southern Spain). Applied Geochemistry, 23: 846-862.

IBGE - INSTITUTO BRASILEIRO DE GEOGRAFIA E ESTATÍSTICA. 2010. Dados do Censo demográfico 2010 publicados no Diário Oficial da União do dia 24/11/2010.

INMET - INSTITUTO NACIONAL DE METEOROLOGIA. Balanço hídrico e dados climatológicos. Mapa Climatológico de Precipitação Pluviométrica Acumulada Anual (1931-1990), 2011 e 2012. Disponível em: $<$ www.inmet.gov.br>. Acesso em: 10 mar. 2016.

JARQUÍN-YAÑEZ, L., MEJÍA-SAAVEDRA, J. J., MOLINA-FRECHERO, N., GAONA, E., ROCHA-AMADOR, D. O., LÓPEZGUZMÁN, O. D., MOLINA, R. 2015. Association between Urine Fluoride and Dental Fluorosis as a Toxicity Factor in a Rural Community in the State of San Luis Potosi. The Scientific World Journal, 647184: 1-6.

LANDIM, P. M. B. 2011. Análise estatística de dados geológicos multivariados. Editora Oficina de Textos, 208pp.

LARQUIN, N.L., ÁlVAREZ, M.L., COCA, A.M.D., VALE, L.G., BETANCOURT, J.C. 2015. Fluorosis dental en escolares de una zona rural de Camagüey. Revista Electrónica Dr. Zoilo E. Marinello Vidaurreta, 40: 1-6.

LIBÂNIO, M. 2016. Fundamentos de qualidade e tratamento de água. $4^{\mathrm{a}}$ ed. Átomo.

LIMA, A. S. 2010. Composição e origem das águas minerais naturais: exemplo de Caldas da Saúde. Almedina, Coimbra, 246 pp.

LOGAN, J. 1965. Interpretação de Análises Químicas da Água. U.S. Agency for International Development, Recife, 75pp.

LIU, F., SONG, X., YANG, L., ZHANG, Y., HAN, D., MA, Y., BU, H. 2015. Identifying the origin and geochemical evolution of groundwater using hydrochemistry and stable isotopes in the Subei Lake Basin, Ordos energy base, Northwestern China. Hydrol. Earth Syst. Sci., 19: $551-565$. 
LOUSADA, E.O.; CAMPOS, J.E.G. 2011. Estudos isotópicos em águas subterrâneas do Distrito Federal: subsídios ao modelo conceitual de fluxo. Revista Brasileira de Geociências, 41: 355-365.

MATÍAS-CERVANTES, C. A., LÓPEZ-LEÓN, S., MATÍAS-PÉREZ, D., GARCÍA-MONTALVO, I. A. 2018. El aluminio empleado en el tratamiento de aguas residuales y su posible relación con enfermedad de Alzheimer. Journal of Negative and No Positive Results, 3: 139143.

MENDES, B.; OLIVEIRA, J.F.S. 2004. Qualidade da água para o consumo humano. Lidel, Edições Técnicas, Lisboa, 640 pp.

MERKEL, B. J., PLANER-FRIEDRICH, B. 2012. Geoquímica de águas subterrâneas: um guia prática de modelagem de sistemas aquáticos naturais e contaminados. Campinas, SP: Ed. Unicamp, $244 \mathrm{pp}$.

MERLIVAT, L.; JOUZEL, J. 1979. Global climatic interpretation of the deuterium-oxygen 18 relationship for preciptation. Geophysical Research, 84: 5029-5033.

MIRANDA, L. L. F., MONTEIRO, M. D., CAVAlCANTI, J. C. C., VAlLE, C. R. O., SILVA, J. C. 1976. Projeto Fluorita da Serra do Ramalho. Salvador-Ba, SME: CBPM, Convênio SME/CBPM; 1976. 92p

MISI, A., IYER, S.S., COELHO, C.E.S., TASSINARI, C.C., FRANCA- ROCHA, W.J., GOMES, A.S.R., CUNHA, I.A., TOULKERIDIS, T., SANCHES, A. L.A. 2000. Metalogenic evolution model for the lead-zinc deposits of the Meso and Neoproterozoic sedimentary basins of the São Francisco Cráton, Bahia and Minas Gerais, Brazil. Revista Brasileira de Geociências, 30: 302-305.

MISI, A., KAUFMAN, A. J., VEIZER, J., POWIS, K., AZMY, K., BOGGIANI, P. C., CLAUDIO, G., TEIXEIRA, J. B. G., SANCHES, A.L., IYER, S. S. 2007. Chemostratigraphic Correlation of Neoproterozoic successions in South America. Chemical Geology, 237: 161185.

MISI, A., KAUFMAN, A. J., AZMY, K., DARDENNE, M. A., SIAL, A. N.,; DE OLIVEIRA, T. F. 2011. Neoproterozoic successions of the Sao Francisco Craton, Brazil: the Bambui, Una, Vazante and Vaza Barris/Miaba groups and their glaciogenic deposits. Geological Society. Memoirs (London), 36: 509-522.

MORAL, F., CRUZ-SANJULIÁN, J. J., OLÍAS, M. 2008. Geochemical evolution of groundwater in the carbonate aquifers of Sierra de Segura (Betic Cordillera, southern Spain). Journal of Hydrology, 360: 281-296.

PARKHURST, D. L.; APPELO, C. A. J. 2013. Description of input and examples for PHREEQC version 3-A computer program for speciation, batch-reaction, one-dimensional transport, and inverse geochemical calculations:
U.S. Geological Survey Techniques and Methods, book 6, chap. A43, 497 p. Disponível em: < http://pubs.usgs.gov/tm/06/a43>. Acesso em: 25 jul. 2013.

PIPER, A.M. 1944. A graphic procedure in the geochemical interpretation of water analyses. Eos, Transactions American Geophysical Union, 25: 914- 928.

RAO, N. S. 2011. High-fluoride groundwater. Environmental monitoring and assessment, 176: 637-645.

REYNOLDS-VARGAS, J., FRAILE-MERINO, J., HIRATA, R. 2006. Trends in nitrate concentrations and determination of their origin using stable isotopes $(18 \mathrm{O}$ and $15 \mathrm{~N})$ in groundwater of the western Central Valley, Costa Rica. Ambio: A Journal of the Human Environment, 35: n. 5, p. 229-236.

RIBEIRO, D. M.; ROCHA, W. F.; GARCIA, A. J. V. Vulnerabilidade Natural à Contaminação dos Aquíferos DA Sub. Bacia do Rio Siriri, Sergipe. 2011. Águas Subterrâneas, 25: 1, p.91-102.

ROISENBERG, C., VIERO, A. P., ROISENBERG, A., SCHWARZBACH, M. S., MORANTE, I. C. 2003. Caracterização geoquímica e gênese dos principais íons das águas Subterrâneas de Porto Alegre, RS. Revista Brasileira de Recursos Hidricos, 8: 137-147.

ROZANSKI, K., ARAGUAS, L., GONFIANTINI, R. 1993. Isotopic patterns in modern global precipitation. AGU Geophys. Monogr. 78: 1-37.

SÁNCHEZ, D., BARBERÁ, J. A., MUDARRA, M., ANDREO, B. 2015. Hydrogeochemical tools applied to the study of carbonate aquifers: examples from some karst systems of Southern Spain. Environ Earth Sci, 74: 199-2015.

SANTOS, R. A. 2017. Hidrogeoquímica dos Domínios Cársticos de Irecê, Bahia-Brasil. Tese de Doutorado, Universidade Federal da Bahia. Instituto de Geociências, Salvador, Brasil, 82p.

SILVA, R. D. C. A. D.; ARAÚJO, T. M. D. Qualidade da água do manancial subterrâneo em áreas urbanas de Feira de Santana (BA). 2003. Ciência; Saúde Coletiva, 8: 4, 1019-1028.

SILVA JÚNIOR, G.C.; CUSTODIO, E. 2010. Hidrogeoquímica e Isotopía Ambiental del Sector Noreste de la Serra de Tramuntana, Isla de Mallorca (España). Ingeniería del Agua, 17: $1-30$.

SPIRO, T.G.; STIGLIANI, W. M. 2009. Química ambiental. 2. ed. São Paulo: Pearson Prentice Hall.

VARNIER, C., IRITANI, M. A., VIOTTI, M., ODA, G. H.,; FERREIRA, L. M. R. 2010. Nitrato nas águas subterrâneas do Sistema Aquífero Bauru, área urbana do município de Marília (SP). Revista do Instituto Geológico, 31: 1-21.

VAZQUEZ-ALVARADO, P., PRIETO-GARCÍA, F., CORONEL- OLIVARES, C., GORDILLOMARTINEZ, A.J., ORTIZ- ESPINOSA, R.M. 2010 Fluorides and dental fluorosis in students from Tula de Allende Hidalgo, Mexico. Journal 
of Toxicology and Environmental Health Sciences, 2: 24-31.

VELÁSQUEZ, L.N.M., FANTINEL, L.M., FERREIRA, E.F., CASTILHO, L.S., UHLEIN, A., VARGAS, A.M.D., ARANHA, P.R.A. 2006. Fluorose dentária e anomalias de flúor na água subterrânea no município de São Francisco, Minas Gerais. In: Silva, C. R. da et al. (Org). Geologia Médica no Brasil. Rio de Janeiro: CPRM - Serviço Geológico do Brasil. 6: $110-117$.
WALTON, J. R. 2007. An aluminum-based rat model for Alzheimer's disease exhibits oxidative damage, inhibition of PP2A activity, hyperphosphorylated tau, and granulovacuolar degeneration. Journal of inorganic biochemistry, 101: $1275-1284$.

WHO. World Health Oganization. 2006. Guidelines for drinking-water quality. Geneva: Word Health Organization. 